\title{
High-end climate change impact on European runoff and low flows - exploring the effects of forcing biases
}

\author{
Lamprini V. Papadimitriou ${ }^{1}$, Aristeidis G. Koutroulis ${ }^{1}$, Manolis G. Grillakis ${ }^{1}$, and Ioannis K. Tsanis ${ }^{1,2}$ \\ ${ }^{1}$ Technical University of Crete, School of Environmental Engineering, Chania, Greece \\ ${ }^{2}$ McMaster University, Department of Civil Engineering, Hamilton, ON, Canada \\ Correspondence to: Ioannis K. Tsanis (tsanis@ @ydromech.gr)
}

Received: 27 May 2015 - Published in Hydrol. Earth Syst. Sci. Discuss.: 31 July 2015

Revised: 28 March 2016 - Accepted: 5 April 2016 - Published: 10 May 2016

\begin{abstract}
Climate models project a much more substantial warming than the $2{ }^{\circ} \mathrm{C}$ target under the more probable emission scenarios, making higher-end scenarios increasingly plausible. Freshwater availability under such conditions is a key issue of concern. In this study, an ensemble of Euro-CORDEX projections under RCP8.5 is used to assess the mean and low hydrological states under $+4{ }^{\circ} \mathrm{C}$ of global warming for the European region. Five major European catchments were analysed in terms of future drought climatology and the impact of $+2{ }^{\circ} \mathrm{C}$ versus $+4{ }^{\circ} \mathrm{C}$ global warming was investigated. The effect of bias correction of the climate model outputs and the observations used for this adjustment was also quantified. Projections indicate an intensification of the water cycle at higher levels of warming. Even for areas where the average state may not considerably be affected, low flows are expected to reduce, leading to changes in the number of dry days and thus drought climatology. The identified increasing or decreasing runoff trends are substantially intensified when moving from the +2 to the $+4^{\circ}$ of global warming. Bias correction resulted in an improved representation of the historical hydrology. It is also found that the selection of the observational data set for the application of the bias correction has an impact on the projected signal that could be of the same order of magnitude to the selection of the Global Climate Model (GCM).
\end{abstract}

\section{Introduction}

Global $\mathrm{CO}_{2}$ emission rates have been following high-end climate change pathways leading to a future global temperature that is likely to surpass the target limit of $2^{\circ} \mathrm{C}$, despite the recent hiatus (England et al., 2015), and reach levels of $+4{ }^{\circ} \mathrm{C}$ and higher at the end of the 21 st century. By that time, the seasonality of river discharge is expected to get more pronounced for one-third of the global land surface, which translates to increased high flows and decreased low flows (Van Vliet et al., 2013). By the mid-century, the hydrological regime is projected to change considerably for a significant part of the global land surface (Arnell and Gosling, 2013). The effect that global warming can have on water resources raises serious concerns about future water availability, especially under the pressure of the growing global population and the consequent increased food production needs. It is projected that the number of people coping with significantly reduced water availability will increase by $15 \%$ globally due to climate change, while the percentage of the global population living under conditions of absolute water scarcity is also projected to increase (Schewe et al., 2014).

In this framework, the future hydrological state needs to be assessed. The runoff production is the component of the hydrological cycle most representative to describe freshwater availability, as it expresses the amount of available water after the evapotranspiration and infiltration losses and before any stream formation process intervenes. Furthermore, ensembles of mean annual and seasonal runoff can provide information about the climate change impact on river flows (Döll and Schmied, 2012). Studies have shown that changes in runoff are not linearly correlated with changes in global mean temperature (Arnell and Gosling, 2013), nor are meteorological droughts with hydrological droughts (van Huijgevoort et al., 2013), concluding that for climate change impact assessments it is fundamental to use an impact model to translate the precipitation derived signal into runoff. 
A substantial number of large-scale climate change impact studies that have been performed recently examine the future hydrological state analysing projections of runoff or river flow. Fung et al. (2011) compared the projected future water availability under +2 and $+4{ }^{\circ} \mathrm{C}$ of global warming, forcing the MacPDM Global Hydrological Model (GHM) with 22 Global Climate Models (GCMs) from the CMIP3 experiment. Arnell and Gosling (2013) performed a global assessment of the climate driven changes in runoff-based hydrologic indicators in the mid-21st century, using multiple scenarios derived from the CMIP3 experiment. Schneider et al. (2013) focused on the impacts of climate change for the European river flows, using data from three bias corrected GCM scenarios. Van Vliet et al. (2013) performed a global assessment of future river discharge and temperature under two climate change scenarios, forcing a GHM with an ensemble of bias corrected GCM output. They found that the combination of lower low flows with increased river water temperature can lead to water quality and ecosystem degradation in the south-eastern US, Europe, eastern China, southern Africa and southern Australia. An investigation of the future trends in flood risk at the global scale was performed by Dankers et al. (2014) and for the European region by Alfieri et al. (2015). Betts et al. (2015) performed a global assessment of the impact posed on river flows and terrestrial ecosystems by climate and land use changes described by four RCPs (Representative Concentration Pathways). Various multi-model hydrological simulations have also been performed, in an attempt to quantify the climate change analysis' uncertainty resulting from the impact model (Hagemann et al., 2013; van Huijgevoort et al., 2013; Dankers et al., 2014).

Currently, global mean temperature has increased $0.85^{\circ} \mathrm{C}$ relative to pre-industrial, and already $18 \%$ of the moderate daily precipitation extremes are attributed to this warming. At $+2{ }^{\circ} \mathrm{C}$ the fraction of the global warming driven precipitation extremes is projected to rise up to $40 \%$ (Fischer and Knutti, 2015). The effect of a $2{ }^{\circ} \mathrm{C}$ global warming for the European climate was examined by Vautard et al. (2014). The study revealed that warming in Europe is projected to be higher than the global average of $2^{\circ} \mathrm{C}$. Temperature increases of up to $3{ }^{\circ} \mathrm{C}$ were found for the winter season over northwestern Europe and for the summer months over southern Europe. Heavy precipitation was found to increase over the whole continent for all seasons, with the exception of southern Europe during summer. Prospects of limiting the warming to the $+2{ }^{\circ} \mathrm{C}$ target have become vanishingly small (Sanford et al., 2014) at the same time that many experts believe that we are on the $+4^{\circ} \mathrm{C}$ path (Betts et al., 2011, 2015). The $+4{ }^{\circ} \mathrm{C}$ global warming scenario is also translated into more intense temperature increases in Europe, especially for the summer season (World Bank, 2014).

Significant climate change induced alterations are projected for the flow regime in Europe, with the most pronounced changes in magnitude projected for the Mediter- ranean region and the northern part of the continent (Schneider et al., 2013). Moreover, considering that southern Europe is identified as a possible hotspot where the fraction of land under drought will increase substantially (Prudhomme et al., 2014), along with global temperature rise exceeding $+2{ }^{\circ} \mathrm{C}$, concerns for future water availability in Europe are rising. Prolonged water deficits during long-term droughts surpass the resilience of the hydrological systems and are a significant threat to water resource security in Europe (Parry et al., 2012). In the Euro-Mediterranean regions the severity of droughts has increased during the past 50 years, as a consequence of greater atmospheric evaporative demand resulting from temperature rise (Vicente-Serrano et al., 2014). Besides southern European areas, the north-western and centraleastern regions appear more drought prone than the rest of Europe (Bonaccorso et al., 2013). Streamflow projections indicate more severe and persistent droughts in many parts of Europe due to climate change, except for the northern and north-eastern parts of the continent. The opposite is projected for the middle and northern parts, with a highly significant signal of reduced droughts that may be reversed due to intensive water use (Forzieri et al., 2014). Consequently European cropland affected by droughts is projected to increase 7-fold (up to $700000 \mathrm{~km}^{2} \mathrm{yr}^{-1}$ ) at about $+3^{\circ}$ of global warming (Ciscar et al., 2014) compared to the situation of the last decades. Similarly, under the same warming level, the European population affected by droughts is expected to increase by a factor of 7 , overtaking 150 million $\mathrm{yr}^{-1}$.

GCM outputs, used as input in impact models to assess the effects of climate change, feature systematic errors and biases. To deal with these, several bias correction techniques have been developed to statistically adjust the GCM output against observations. This process adds another level of uncertainty in the chain of climate to impact modelling that has to be investigated and communicated to the impact research communities. Ehret et al. (2012) acknowledge the fact that inherent climate models' biases render them unsuitable for direct use in climate change impact assessments, but express scepticism towards adopting bias correction as a standard undisputed procedure. They argue that bias adjustment hides rather than reduces the uncertainty, as the narrowing of the uncertainty range is not supported by any physical explanation. Teutschbein and Seibert (2012) also accept the need for bias correction but raise awareness towards the increased uncertainty derived from adding this step to the modelling chain. Ehret et al. (2012) introduce the issue of how "correct" is the data set used as a baseline for the bias adjustment. Haerter et al. (2011) underline the fact that the statistical adjustments applied to GCM data with bias correction are bounded to the timescale selected for the adjustment and might have adverse effects on the statistics of another timescale. Haerter et al. (2011) also accentuate that one significant assumption is made when present-day-based bias correction methods are applied to climate scenario simulations: that of the bias stationarity throughout the future 
decades. Teng et al. (2015) argue that errors in bias corrected precipitation are inherited and augmented in modelled runoff.

The major tools for the investigation of large-scale hydrological changes due to climate change are global hydrological models (GHMs) and/or land surface models (LSMs). According to the classification proposed by Haddeland et al. (2011), the models that solve the water balance are considered as GHMs and the models that solve both the water and energy balance are categorised as LSMs. The LSM JULES (Joint UK Land Environment Simulator; Best et al., 2011) has been implemented for many recent climate change impact and model inter-comparison studies (Hagemann et al., 2013; Davie et al., 2013; Dankers et al., 2014; Prudhomme et al., 2014; Harding et al., 2014).

The scope of this work is to assess future water availability and identify drought conditions in the European region under high-end scenarios of climate change. Transient hydrological simulations for the period 1971 to 2100 were performed by forcing the JULES model with five Euro-CORDEX (Coordinated Downscaling Experiment over Europe) climate projections. Water availability is described by the output of runoff production. In our analysis the model results are mainly interpreted statistically, aiming to express the changes found in the projected future periods with respect to the historical baseline state rather than describing future regimes with absolute numbers. The research objectives set by this study are the following.

i. To identify changes posed on the hydrological cycle (mean state and lower extremes) at $+4{ }^{\circ} \mathrm{C}$ global warming compared to a baseline situation, and relative to the target of $2{ }^{\circ} \mathrm{C}$ warming.

ii. To analyse the effect of bias correction on projected hydrological simulations. To achieve this, both raw and bias corrected Euro-CORDEX data were used as input forcing in the impact model.

iii. To assess the effect of the observational data set used for bias correction.

iv. To identify climate change induced changes in drought climatology at the basin scale.

\section{Data and methods}

Hydrological simulations were performed with the JULES land surface model driven by Euro-CORDEX climate scenarios. To warm up the model, 10 spin-up cycles from 1955 to 1960 were run. A daily time step was employed for all the model runs. JULES was set up at the spatial resolution of the forcing Euro-CORDEX data, which was $0.44^{\circ}$. The model output was regridded to match a $0.5^{\circ} \times 0.5^{\circ}$ grid.

Brief descriptions of the climate data and the impact model are included in the following sections.

\subsection{Climate data}

Projections from five Euro-CORDEX experiments under the Representative Concentration Pathway RCP8.5 scenario were used as input to JULES. The climate models were selected so as to cover the range of model sensitivity, as expressed by the index of equilibrium climate sensitivity (ECS) which ranges from 2.1 to $4.7 \mathrm{~K}$ for the CMIP5 ensemble (Andrews et al., 2012). ECS is a useful metric of the response of a climate model, in terms of air temperature change, to a doubling of the atmospheric $\mathrm{CO}_{2}$ concentration (Andrews et al., 2012). Another factor for selecting the participating climate models was the availability of GCM downscaled at the spatial resolution of $0.44^{\circ}$.

Historical and projected time slices comprise 30 years of simulations, for which one time slice average is extracted. The historical or baseline time slice covers the period from 1976 to 2005 . The projected time slice varies between the models. The definition for determining the projected time slice here is to take the 30-year average of the slice centered on the year where the +4 (or +2 ) specific warming level (SWL) is exceeded. The reference period for the calculation of the SWL is the pre-industrial state and specifically the period from 1861 to 1880 . For three of the selected scenarios the $+4 \mathrm{SWL}$ is achieved outside the temporal extend of this study; thus, the last 30-year period available is considered instead (2071-2100). The SWL exceeded during that period for the models that reach +4 after 2100 is shown in Table 1. For reasons of consistency in terminology the time slice of all models describing the greater SWL achieved will be referred to as the $+4 \mathrm{SWL}$ time slice.

Using the SWL concept constitutes the results independent of the time that the warming occurs. Although by definition of the SWL, the models reach the same level of warming in their time slices, the different model sensitivity reflects on the evolution of temperature in the time slice, as more sensitive models are expected to have higher rates of changes in the period before and after a specific SWL is achieved compared to the less sensitive models. Moreover, considering models of different ECS is important to express the range of variables other than temperature forcing produced by the GCMs (e.g. radiation).

The five scenarios along with information on the time slices extracted for our analysis and the corresponding exceeded warming levels and ECS indices are shown in Table 1 . Two widely used observational data sets were used to adjust the biases of the RCM precipitation and temperature data. The first data set was a hybrid data set created by the Inter-Sectoral Impact Model Integration and Intercomparison Project ISI-MIP (Warszawski et al., 2014) that consists of the WFD (Weedon et al., 2010) and WFDEI.GPCC (Weedon et al., 2014) data sets. Additionally, the station data-based European Climate Assessment \& Dataset (ECA \& D) and the ENSEMBLES Observations gridded data set (E-OBS v10; 
Table 1. Euro-CORDEX climate scenarios used to force JULES.

\begin{tabular}{|c|c|c|c|c|c|c|}
\hline & GCM & $\begin{array}{l}+2 \mathrm{SWL} \\
\text { time slice }\end{array}$ & $\begin{array}{l}\text { Exceeded } \\
\text { warming } \\
\text { level }\left({ }^{\circ} \mathrm{C}\right) \text { in } \\
\text { the }+2 \mathrm{SWL} \\
\text { time slice }\end{array}$ & $\begin{array}{l}+4 \mathrm{SWL} \\
\text { time slice }\end{array}$ & $\begin{array}{l}\text { Exceeded } \\
\text { warming } \\
\text { level }\left({ }^{\circ} \mathrm{C}\right) \text { in } \\
\text { the }+4 \mathrm{SWL} \\
\text { time slice }\end{array}$ & $\begin{array}{l}\text { Equilibrium } \\
\text { climate } \\
\text { sensitivity } \\
\text { (K) }\end{array}$ \\
\hline 1 & GFDL-ESM2M & 2040-2069 & 2 & $2071-2100$ & 3.2 & 2.44 \\
\hline 2 & NorESM1 & 2036-2065 & 2 & $2071-2100$ & 3.75 & 2.80 \\
\hline 3 & MIROC5 & 2037-2066 & 2 & $2071-2100$ & 3.76 & 2.72 \\
\hline 4 & IPSL-CM5A & 2018-2047 & 2 & 2055-2084 & 4 & 4.13 \\
\hline 5 & HadGEM2-ES & 2024-2053 & 2 & 2060-2089 & 4 & 4.59 \\
\hline
\end{tabular}

Haylock et al., 2008) were also used for the bias adjustment of the aforementioned climate variables.

\subsection{Bias correction method}

In the present study the multi-segment bias correction (MSBC) method is used to correct the precipitation and temperature data for their biases. A detailed description of the method can be found in Grillakis et al. (2013). This bias correction methodology has the ability to better transfer the observed precipitation statistics to the raw GCM data. The method utilises multiple discrete segments on the cumulative density function (CDF) to fit multiple theoretical distributions, as opposed to the commonly used single transfer function at the entire CDF space. Pragmatically, the method eliminates to a large extent the bias in mean precipitation, while significantly reducing the bias of the higher quantile of the precipitation CDF associated with extreme precipitation events.

\subsection{The JULES land surface model}

JULES is a physically based land surface model that was established in 2006. It is comprised of two parts: the Met Office Surface Exchange Scheme (MOSES; Cox et al., 1998) and the Top-down Representation of Interactive Foliage and Flora Including Dynamics (TRIFFID; Cox, 2001) component. MOSES is an energy and water balance model which is JULES' forerunner, and TRIFFID is a dynamic global vegetation model (Best et al., 2011; Clark et al., 2011; Cox, 2001). In our model application for this study we do not examine vegetation dynamics thus we are focusing on the MOSES component of JULES.

The meteorological forcing data required for running JULES are downward shortwave and longwave radiation, precipitation rate, air temperature, wind speed, air pressure and specific humidity (Best et al., 2011).

JULES has a modular structure, which makes it a flexible modelling platform, as there is the potential for replacing modules or introducing new modules within the model. The physics modules that comprise JULES include the following themes: surface exchange of energy fluxes, snow cover, sur- face hydrology, soil moisture and temperature, plant physiology, soil carbon and dynamic vegetation (Best et al., 2011), with the latter being disabled for this application.

In JULES, each grid box is represented by a number of surface types, each one represented by a tile. JULES recognises nine surface types (Best et al., 2011), of which five are vegetation surface types (broadleaf trees, needleleaf trees, C3 (temperate) grasses, C4 (tropical) grasses and shrubs) and four are non-vegetated surface types (urban, inland water, bare soil and ice). A full energy balance equation including constituents of radiation, sensible heat, latent heat, canopy heat and ground surface heat fluxes is calculated separately for each tile and the average energy balance for the grid box is found by weighting the values from each tile (Pryor et al., 2012).

In JULES the default soil configuration consists of four soil layers of thicknesses $0.1,0.25,0.65$ and $2.0 \mathrm{~m}$. This configuration however can be altered by the user. The fluxes of soil moisture between each soil layer are described by Darcy's law and a form of Richards' equation (Richards, 1931) governs the soil hydrology. Runoff production is governed by two processes: infiltration excess surface runoff and drainage through the bottom of the soil column, a process calculated as a Darcian flux assuming zero gradient of matric potential (Best et al., 2011). There is also the option of representing soil moisture heterogeneity. In that case total surface runoff also includes saturation excess runoff. The model allows for two approaches to introduce sub-gridscale heterogeneity into the soil moisture: (1) use of TOPMODEL (Beven and Kirkby, 1979), where heterogeneity is taken into account throughout the soil column, or (2) use of PDM (Moore, 1985), which represents heterogeneity in the top soil layer only (Best et al., 2011). Calculation of potential evaporation follows the Penman-Monteith approach (Penman, 1948). Water held at the plant canopy evaporates at the potential rate while restrictions of canopy resistance and soil moisture are applied for the simulation of evaporation from soil and plant transpiration from potential evaporation.

JULES simulates fluxes in the vertical direction only. For hydrological applications this means that the model calculates runoff production in each grid box which needs to be 
routed to estimate streamflow. The standard version of the JULES model until very recently (February 2015) did not account for a routing mechanism. To overcome this model limitation, we use a conceptual lumped routing approach based on triangular filtering in order to delay runoff response. This is applied after discriminating the grid boxes that contribute to runoff production of a specific basin from the gridded model output. Determination of grid boxes upstream of the gauging station location is implemented using the TRIP river routing scheme (Oki and Sud, 1998).

JULES has been used in many recent studies as a tool for evaluating the exchange of water, energy and carbon fluxes between the land surface and the atmosphere. Van den Hoof et al. (2013) assessed JULES' performance in simulating evaporative flux (and its partitions) and carbon flux in temperate Europe. Marthews et al. (2012) implemented JULES in tropical forests of the Andes-Amazon to simulate all components of carbon balance and study possible flux variations between sites of different altitudes. Zulkafli et al. (2013) implemented JULES in a humid tropical mountain basin of the Peruvian Andes-Amazon. MacKellar et al. (2013) evaluated JULES, implemented in a region of southern Africa, concerning its ability to simulate the catchment streamflow. In the study of Bakopoulou et al. (2012), the sensitivity of the JULES outputs to the soil parameters of the model at a point scale was estimated. Dadson et al. (2010) sought to quantify the feedback between wetland inundation and heat and moisture fluxes in the Niger inland delta by adding an overbank flow parameterization into JULES. Burke et al. (2013) used JULES to simulate retrospectively the pan-Arctic changes in permafrost and Dankers et al. (2011) assessed JULES' performance in simulating the distribution of surface permafrost in large-scale catchments. In a study by Jiménez et al. (2013) soil moisture modelled with JULES is evaluated against satellite soil moisture observations.

Other studies give insight into the hydrological performance of JULES specifically. Blyth et al. (2011) extensively evaluated the JULES model for its ability to capture observed fluxes of water and carbon. Concerning discharge, their findings suggest that for the European region seasonality is captured well by the model. For temperate regions (like most of central Europe) the model exhibited a tendency towards underestimating river flows due to overestimation of evapotranspiration. Prudhomme et al. (2011) assessed JULES' ability in simulating past hydrological events over Europe. In general terms the model was found to capture the timing of major drought events and periods with no large-scale droughts present were also well reproduced. The model showed a positive drought duration bias, more profoundly present in northwestern Spain and eastern Germany-Czech Republic. Prudhomme et al. (2011) argue that this feature is related to overestimation of evaporation by the model. For regions where droughts tend to last longer, JULES exhibited a better ability to reproduce the drought events' characteristics. Gudmundsson et al. (2012a) compared nine large-scale hydro- logical models, and their ensemble mean, based on their skill in simulating the interannual variability of observed runoff percentiles in Europe. According to the overall performance (accounting for all examined percentiles and evaluation metrics), JULES was ranked third best out of the 10 models, after the multi-model ensemble mean and the GWAVA model. For low and moderately low flows, expressed as the 5th and 25 th percentiles respectively, JULES is also in the top three models regarding the representation of interannual variability in runoff. In the study of Gudmundsson et al. (2012b), where an ensemble of hydrological models is evaluated for their ability to capture seasonal runoff climatology in three different hydroclimatic regime classes in Europe, JULES exhibits a good performance, comparable to that of the best performing multi-model ensemble mean. In other studies employing multi-model ensembles, focusing on the whole European region (Gudmundsson and Seneviratne, 2015) or a single basin in Europe (Harding et al., 2014; Weedon et al., 2015), JULES' simulations also correspond to these of the other models.

\subsection{Identifying changing climate trends}

For the assessment of the impact of the $+4{ }^{\circ} \mathrm{C}$ warming relative to pre-industrial, the projected time slices are compared to the baseline period in terms of both absolute and percent change. This is done for each ensemble member individually in order to check the variability of the projected changes and also for the ensemble mean. Two hydrologic indicators are tested, the average and the 10th percentile of runoff production.

Average runoff production is a good and widely used indicator of mean hydrological state of a region. The 10th percentile runoff is considered as a representative indicator of the low flow regime (Prudhomme et al., 2011). Consistent low flows (relative to the mean state) are connected with the formation of hydrological drought conditions. Thus the assessment of the changes in low flows could reveal trends towards more intense or/and often extreme lows in the future hydrological cycle. The impact of high-end climate scenarios on average and 10th percentile runoff is presented both as gridded results at the pan-European scale and aggregated at the basin scale for five major European river basins.

The two hydrological indicators were deduced from monthly runoff data. For the analysis of the gridded results at pan-European scale with the SWL time-slice approach, each indicator was computed from the monthly values of all years in the time slice. For the analysis of basin aggregated runoff regimes, the two hydrologic indicators were calculated per year, for all the years of the simulation. This resulted in time series of basin aggregated average and 10th percentile runoff production, spanning from 1971 to 2100 . The trend of the annual time series was investigated employing a linear regression analysis to estimate the sign and the average rate of 


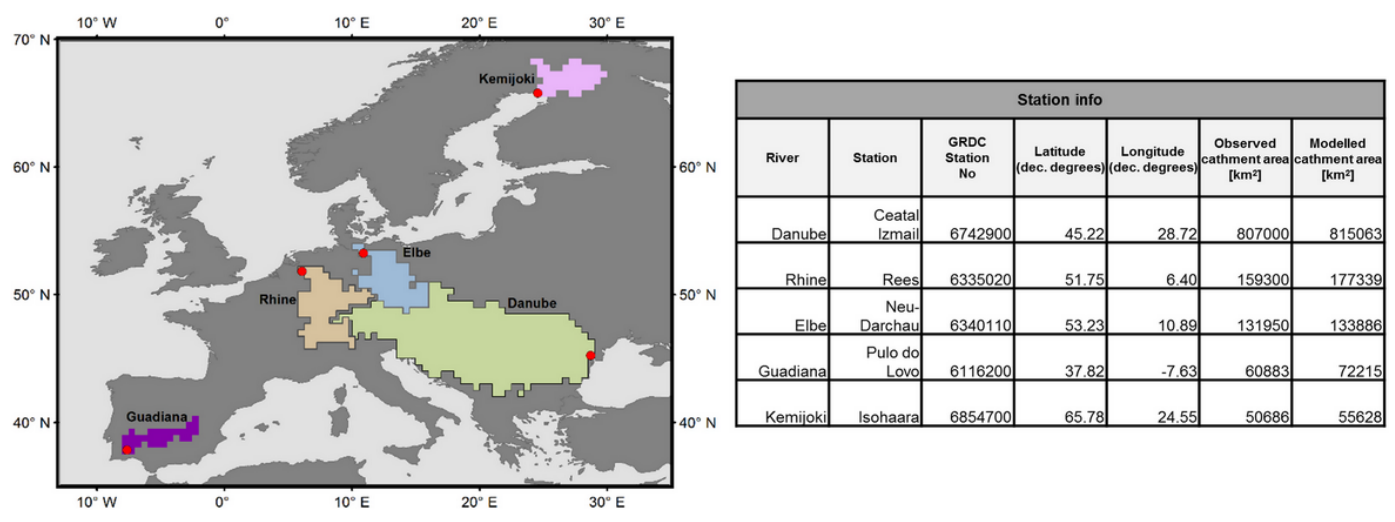

Figure 1. European study domain, tested basins as defined by the model's $0.5^{\circ}$ resolution, gauging stations and general information on the stations.

the trend. The significance of the trend was tested at the $95 \%$ confidence interval via a Student $t$ test.

The Europe study domain along with information on the catchments tested and their corresponding gauging stations are shown in Fig. 1.

\subsection{Examination of drought climatology}

Another aspect of our low flow analysis is to assess changes in drought climatology, i.e. the number of days per year that particular lows in flow occur. This is here done at the basin scale, following the threshold level method to identify days of discharge deficiencies. The threshold level method is a widely used tool for drought identification applications (Fleig et al., 2006; Vrochidou et al., 2013). According to this method, drought conditions are characterised as the periods during which discharge falls below a pre-defined threshold level. In our application, the threshold is varying daily and is established as in Prudhomme et al. (2011): for each Julian day $k$, the 10th percentile of a 31-day window discharge centering at day $k$ is derived, from data of all the years of the baseline period (1976-2005). The daily modelled time series for the whole period simulated (1971-2100) is compared to the daily varying drought limit, and the number of days that fall below the threshold is summed up on an annual basis. The drought threshold is derived from the flows of the baseline period and is applied to both historical and projected flows, in order to capture the climate change induced changes in drought climatology. The regression analysis described in Sect. 2.4 was also applied to the time series of total drought days per year.

\section{Results}

\subsection{Hydrological simulation at pan-European scale with raw Euro-CORDEX forcing data}

Figure 2 shows the average runoff production estimated by JULES forced with the five participating dynamical downscaled GCMs, for each model separately and for the ensemble mean. Measures of model agreement (coefficient of variation between the ensemble members and model agreement on a wetter change in the projected time slice) are also shown in Fig. 2. The change in runoff in the +4 SWL projected time slice with respect to the baseline period is expressed as both absolute and percent relative difference. It is interesting to observe the variations between the models for the historical time slice, with the low climate sensitivity GFDL and NorESM1 exhibiting generally wetter patterns for northern Europe and the Scandinavian Peninsula, and with IPSL describing drier patterns, especially for southern Europe. Concerning the overall agreement of the ensemble members in the baseline period, the coefficient of variation is below 0.5 for most of the European region (Fig. 2, bottom panels), indicating a good agreement of the models. In more detail, the coefficient of variation is lower for the Scandinavian region and is reduced towards the lower latitudes.

For the projected time slice, all models agree in a general pattern of increased runoff production in northern Europe and a small part in central Europe and decreased runoff production in Spain, Greece and parts of Italy. Especially for the negative trends shown in southern Europe it is important that, though small in absolute terms, they increase in magnitude when expressed as a percentage, meaning that small negative changes can pose severe stress in regions where water availability is already an issue.

Concerning the ensemble mean, smoothing of the projected changes due to averaging has revealed clear patterns of change, which however have to be interpreted considering the full spread of the GCM-forced outcomes and the agree- 


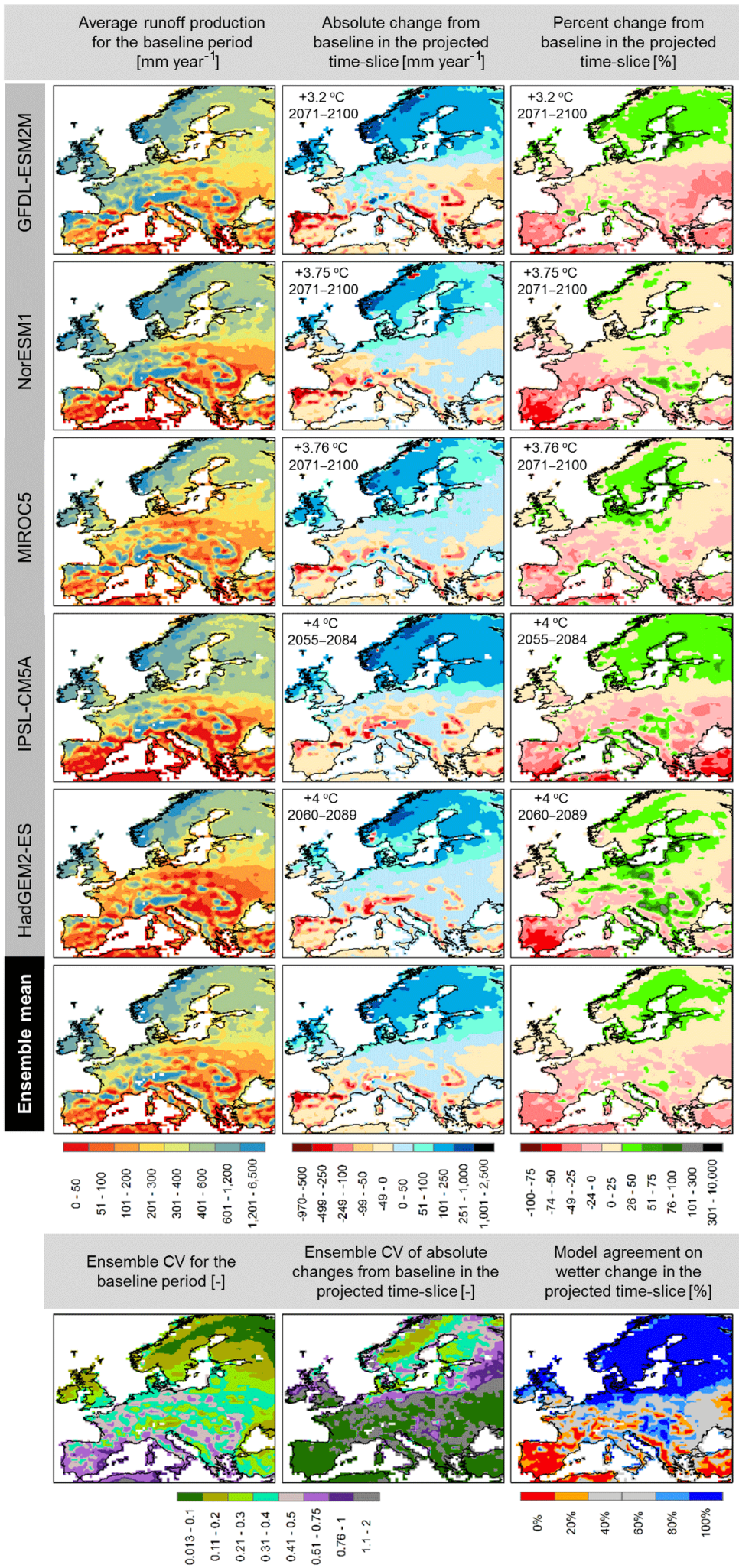

Figure 2. Average runoff production from raw Euro-CORDEX data for all dynamical downscaled GCMs and their ensemble mean. Runoff production averaged over the baseline period (1976-2005) (left column panels), absolute change in runoff in the +4 SWL projected time slice (middle column panels) and percent change in the +4 SWL projected time slice (right column panels). Bottom row panels: coefficient of variation of the ensemble members for the baseline period (left column panels), coefficient of variation of the projected absolute changes in the +4 SWL projected time slice (middle column panels) and model agreement towards a wetter change in the +4 SWL projected time slice. 
ment between them in order to avoid misguided conclusions. Less extreme values are encountered in the ensemble mean of projected changes in runoff, compared to the change projected by each ensemble member individually (Fig. 2). Especially for percent change a clear trend of runoff increase is revealed in northern Europe and decrease in southern Europe, with a mixed pattern for central Europe. Four or five out of the five ensemble members agree on the wetter response in the northern regions and the drier response in the southern part of Europe. The smaller cv value $(\mathrm{cv}<0.1)$ for the southern regions indicates that the models agree more on the value of the change compared to the changes in the Scandinavian region $(0.11<\mathrm{cv}<0.75)$. For central Europe there are areas of reduced agreement, with two models showing a change different in sign than the other three of the ensemble. For the same areas cv has values greater than 1, marking a large spread between the values of the five ensemble members.

Figure 3 has the same features as Fig. 2 but concerns the 10th percentile runoff production instead of the average. The 10th percentile limit is used to describe low flows that are related to the creation of hydrological drought conditions. For 10th percentile runoff, model agreement in the baseline period is notably reduced compared to agreement for average runoff, with the coefficient of variation for most regions exceeding 0.5 , while it exceeds the unity for a large part of Europe. For the +4 SWL projected time slice, according to Fig. 3, all models agree in relative decreases in runoff production in western and southern Europe, which are specifically pronounced in the western Iberian and Balkan peninsulas. Another common trend between the models is the significant increase in runoff production in the Scandinavian Peninsula, with MIROC5 and HadGEM2 being the two ensemble members that expand this wetter climate down to central Europe.

Regarding the ensemble mean changes, percent change in 10th percentile runoff (Fig. 3) shows more significant reductions (up to $100 \%$ ) compared to average runoff (for which changes range between -50 and $50 \%$ ). It is thus deduced that the changes in low flows are more pronounced than the changes in the mean, a conclusion that points towards the overall intensification of the water cycle. The decreasing trend in 10th percentile runoff covers most of the western and southern European area (with 80 to $100 \%$ agreement on the sign of the change), while all models agree in an increase in 10th percentile runoff in the Scandinavian region.

\subsection{Hydrological simulation at pan-European scale with bias adjusted Euro-CORDEX forcing data}

The ensemble mean of average runoff derived from the five participating downscaled GCMs whose temperature and precipitation were bias adjusted according to the WFDEI data set is presented in Fig. 4. Bias adjustment of the forcing data resulted in a drier ensemble mean runoff for the baseline period for $70.40 \%$ of the pan-European land surface, in com- parison to the $26.01 \%$ of the land area that had a wetter response after bias adjustment. The remaining $3.59 \%$ of the European area had changes that were classified as insignificant (see Supplement for details). Projected changes from bias adjusted data exhibit very similar patterns and magnitudes with the raw data derived changes. For some regions in central Europe, where a small negative change is reported by the raw data run, a sign change of the projected difference is documented after bias correction. Lastly, bias correction has a strong positive effect on model agreement as it can be documented from the low values of the coefficient of determination all over Europe, with the exception of the Scandinavian Peninsula, where model disagreement appears increased after bias correction.

In Fig. 5, the effect of bias correction on the representation of the 10th percentile runoff is shown. Some hotspots of pronounced negative changes in western Europe have been eliminated and replaced with milder projected absolute changes. There are areas where sign change is observed (central and central-western Europe); however, it is difficult to interpret this result and correlate it with bias correction as these are also the areas where models show the lowest agreement (coefficient of variation exceeding 1 and agreement towards wetter change 40-60\%). Although the coefficient of variation for the baseline period is considerably reduced compared to the raw data runs, there are still areas of high model uncertainty in the representation of lower flows.

\subsection{Basin averaged runoff regime}

In Fig. 6, annual time series of basin averaged runoff production (average and 10th percentile) for five European basins are shown. These cover the whole length of historical and projected years simulated (1971-2100) in an attempt to identify general trends in average and low runoff, calculating 10year moving averages from the ensemble mean. Results in Fig. 6 include both raw and bias adjusted output; thus, an assessment of the effect of the bias correction on the basinscale hydrology can be made. A common observation for all the basins is that runoff decreases considerably for bias adjusted input forcing.

For the Danube and Guadiana, statistically important negative trends are identified for average runoff $(-0.24$ and $-0.35 \mathrm{~mm} \mathrm{yr}^{-1}$ respectively for raw output, -0.11 and $-0.31 \mathrm{~mm} \mathrm{yr}^{-1}$ respectively for bias adjusted output), which are more pronounced for the 10th percentile runoff. For the Rhine, the identified trends in average runoff production of both raw and bias corrected forcing are not statistically significant. In contrast, the 10th percentile runoff production in the Rhine exhibits statistically significant decreasing trends, for both raw $\left(-0.74 \mathrm{~mm} \mathrm{yr}^{-1}\right)$ and bias corrected $\left(-0.50 \mathrm{~mm} \mathrm{yr}^{-1}\right)$ outputs. For the Elbe, raw output gives an insignificant trend in average runoff and a slight decreasing trend for 10th percentile runoff. Bias corrected data result in a small but statistically significant increasing trend 


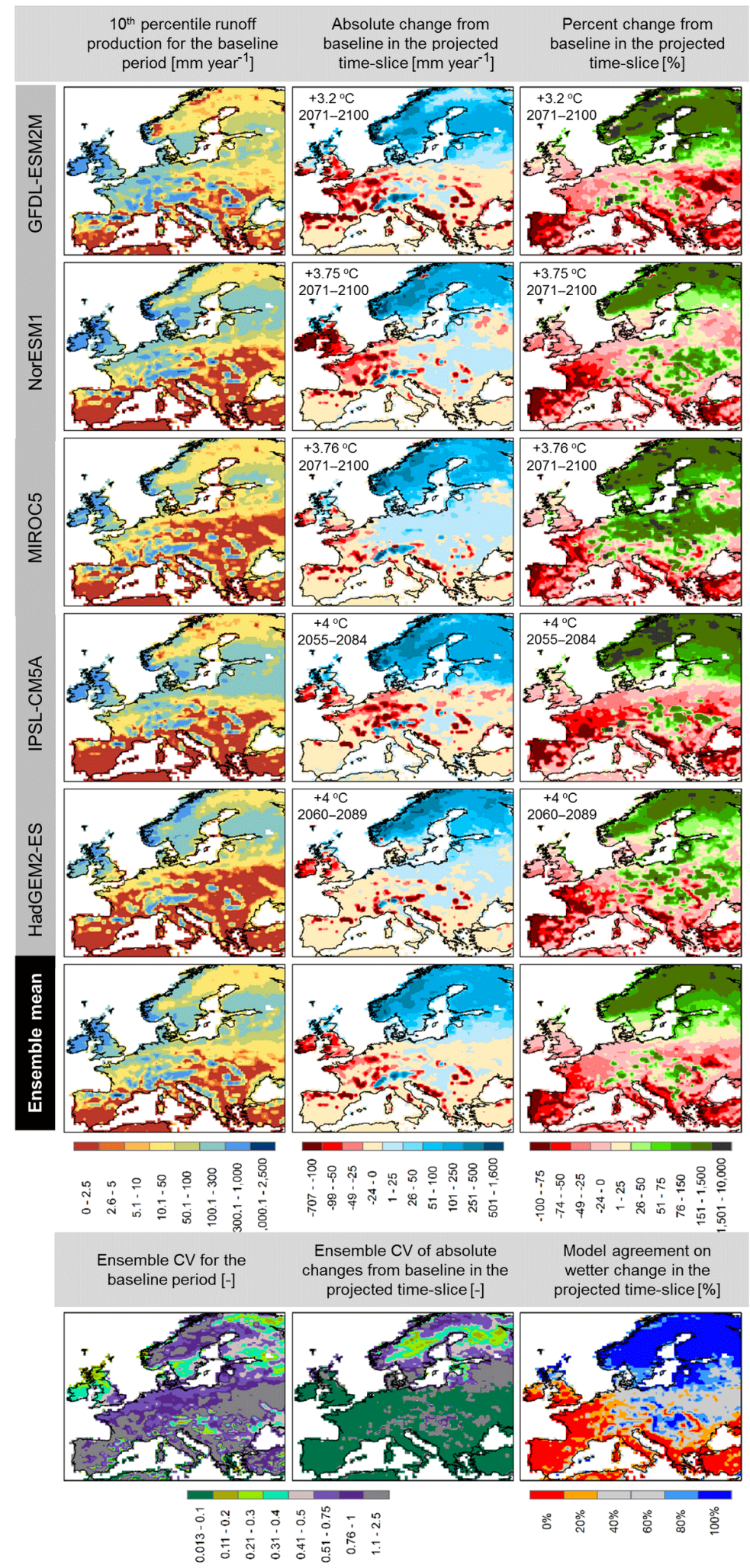

Figure 3. 10th percentile of runoff production from raw Euro-CORDEX data for all dynamical downscaled GCMs and their ensemble mean. 10th percentile runoff production derived on an annual basis and averaged over the baseline period (1976-2005), absolute change in 10th percentile runoff in the $+4 \mathrm{SWL}$ projected time slice (middle column panels) and percent change in the +4 SWL projected time slice (right column panels). Bottom row panels: coefficient of variation of the ensemble members for the baseline period (left column panels), coefficient of variation of the projected absolute changes in the +4 SWL projected time slice (middle column panels) and model agreement towards a wetter change in the +4 SWL projected time slice. 


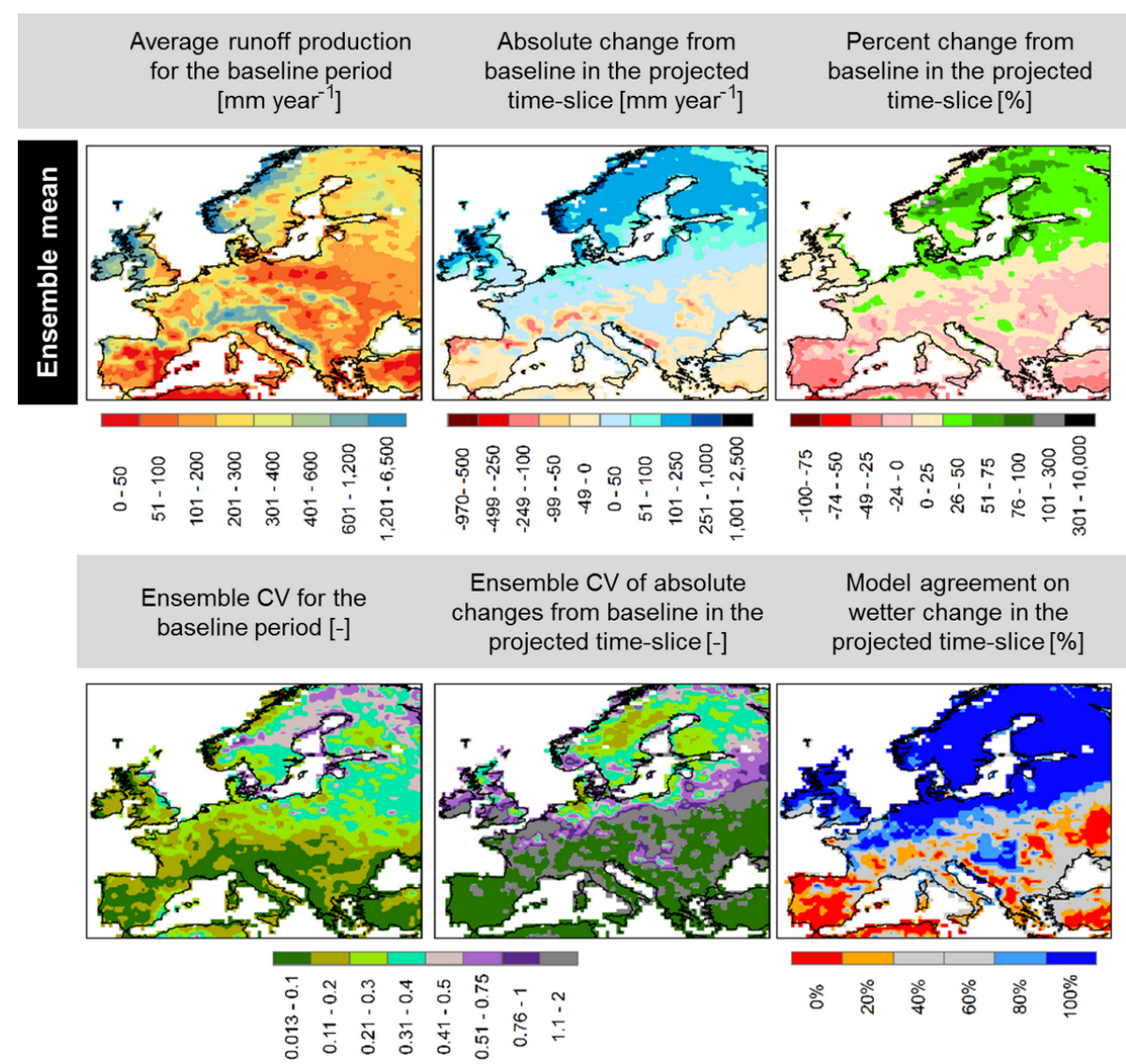

Figure 4. Ensemble mean of average runoff production from Euro-CORDEX data bias adjusted against the WFDEI data set. Top row panels: runoff production averaged over the baseline period (1976-2005) (top row panels), absolute (middle row panels) and percent change (bottom row panels) in ensemble mean runoff in the $+4 \mathrm{SWL}$ projected time slice. Bottom row panels: coefficient of variation of the ensemble members for the baseline period (left column panels), coefficient of variation of the projected absolute changes in the +4 SWL projected time slice (middle column panels) and model agreement towards a wetter change in the +4 SWL projected time slice.

$\left(0.18 \mathrm{~mm} \mathrm{yr}^{-1}\right)$ in annual average runoff, while for 10th percentile runoff the trend is decreasing $\left(-0.06 \mathrm{~mm} \mathrm{yr}^{-1}\right.$, statistically significant). For Kemijoki average and low flows, of raw and bias adjusted forcing, all exhibit statistically significant increasing trends.

Basin-scale average annual runoff production for raw and bias adjusted Euro-CORDEX data as well as the $+4^{\circ} \mathrm{C}$ absolute and percent change for each ensemble member and ensemble mean are included in Table 2. Similar information but for low flows (10th percentile) is presented in Table 3. In Tables S1 and S2 in the Supplement, the results of the linear regression applied to the average and 10th percentile runoff time series for the estimation of the trend and its significance can be found.

\subsection{Drought climatology at basin scale}

Figure 7 shows the results of the drought threshold level method analysis for the five study basins, for raw and bias corrected output. For each year, the number of days under the historical drought threshold has been counted. This allows a comparison of the tendency towards the formation of drought conditions between the historical period and the projected period. As this is a statistically oriented interpretation of our data, we can see that the differences between raw and bias corrected time series are very small, especially compared to the difference in the magnitude of their absolute values. For the Danube, Rhine and Guadiana, strong rising trends (all statistically significant) were identified in the time series of ensemble mean of days under threshold per year. Before bias correction these were $0.43,0.37$ and $0.52{\text { day } \mathrm{yr}^{-1} \text { for }}^{-1}$ the three basins respectively and changed to $0.39,0.39$ and 0.38 day $\mathrm{yr}^{-1}$ respectively after bias correction. For the Elbe, non-bias corrected data give a slight but statistically significant increasing trend $\left(0.14\right.$ day $\left.\mathrm{yr}^{-1}\right)$, in contrast to bias corrected output that shows a statistically insignificant trend. For Kemijoki strong decreasing (statistically significant) trends are found for both for raw $\left(-0.20 \mathrm{day} \mathrm{yr}^{-1}\right)$ and bias corrected $\left(-0.18\right.$ day $\left.\mathrm{yr}^{-1}\right)$ data. Table $\mathrm{S} 3$ tabulates the results of the linear regression applied to time series of ensemble 


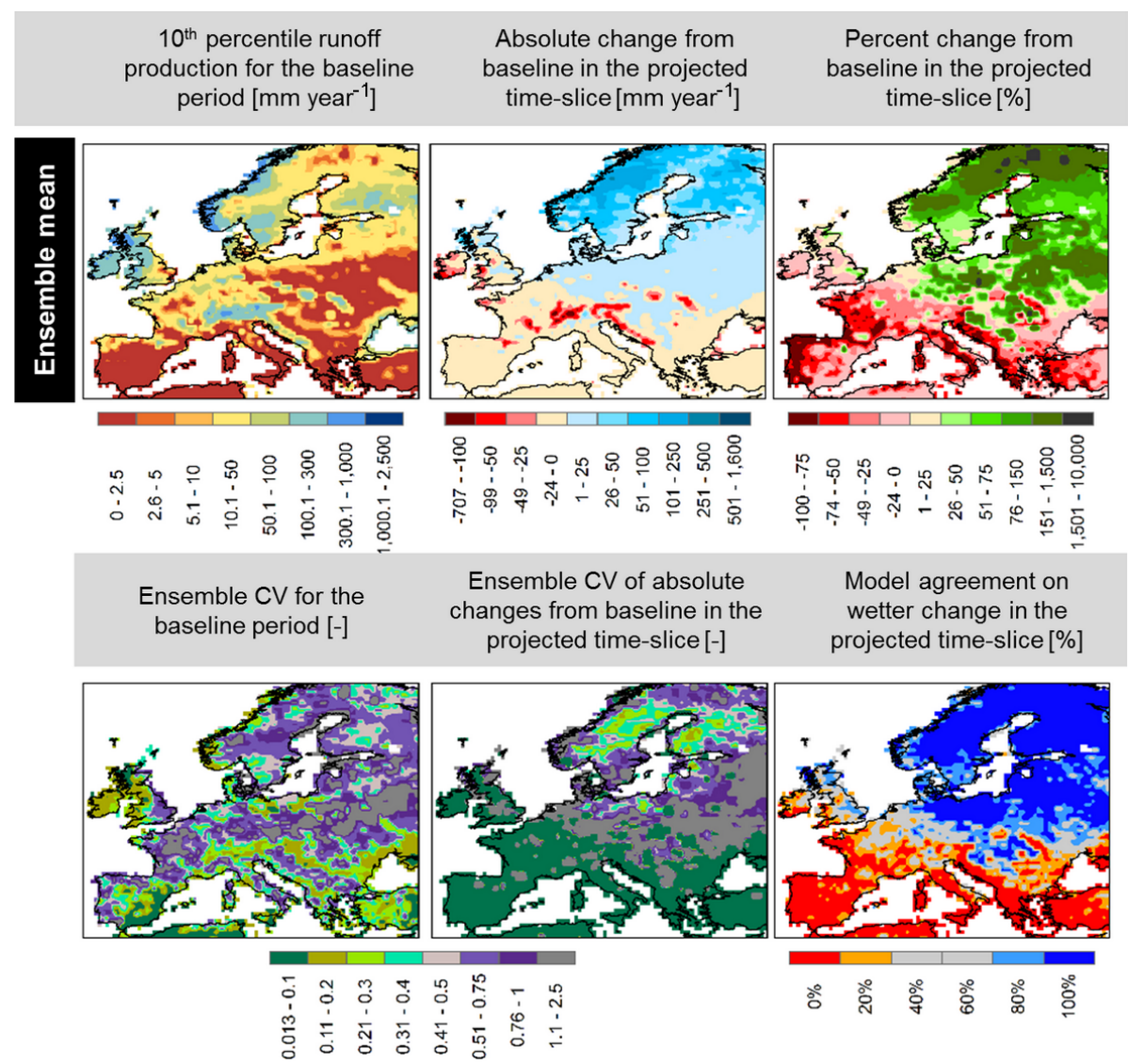

Figure 5. Ensemble mean of 10th percentile runoff production from Euro-CORDEX data bias adjusted against the WFDEI data set. Top row panels: 10th percentile runoff production derived on an annual basis averaged over the baseline period (1976-2005) (top row panels), absolute (middle row panels) and percent change (bottom row panels) in ensemble mean runoff in the +4 SWL projected time slice. Bottom row panels: coefficient of variation of the ensemble members for the baseline period (left column panels), coefficient of variation of the projected absolute changes in the +4 SWL projected time slice (middle column panels) and model agreement towards a wetter change in the +4 SWL projected time slice.

mean of days under threshold per year for the estimation of the time series' trend and its significance.

\subsection{Impacts of $4^{\circ} \mathrm{C}$ warming relative to $2^{\circ} \mathrm{C}$ warming}

Figure 8 shows the basin average runoff production for raw and bias corrected Euro-CORDEX data with respect to the corresponding SWL in degrees Celsius. This analysis considers the runoff values corresponding to the +2 and $+4{ }^{\circ} \mathrm{C}$ SWLs, the latter ranging from 3.2 to 4 between the GCMs, and also the SWL achieved by each participating GCM in the baseline period $\left(0.3-0.5^{\circ} \mathrm{C}\right)$. It is thus allowing us to examine the changes in basin runoff as temperature increases and to compare the effect of different SWLs.

Comparing the annual average runoff production for raw and bias corrected input forcing, it is clear that bias corrected output exhibits a considerably reduced range, which translates into increased model agreement for the basins of the Danube, Rhine, Elbe and Guadiana. In Kemijoki basin the bias adjusted output has a greater range than the raw output.
Concerning the range of the low flows, an increase in model agreement for the bias corrected forcing is observed for all basins.

Examining the changes in annual average runoff, a slight decreasing trend can be identified for the Danube and a slight increasing trend for the Elbe, while for the Rhine there is no clear trend present. In contrast, the Guadiana and Kemijoki exhibit strong decreasing and increasing trends respectively. The falling trend in the Guadiana is marginally intensified between +2 and +4 SWL compared to 0 to +2 SWL. The rising trend in Kemijoki does not have evident differences between +2 and $+4{ }^{\circ} \mathrm{C}$.

According to the results in Fig. 8, the 10th percentile runoff in the Danube and Rhine decreases as SWLs increase, while the opposite trend is observed for the low flows in Kemijoki. For the Elbe the raw results show an intense decreasing trend up to $+2 \mathrm{SWL}$ which continues more moderately until $+4 \mathrm{SWL}$, in contrast to the bias corrected output that shows milder changes with temperature increase. For the 


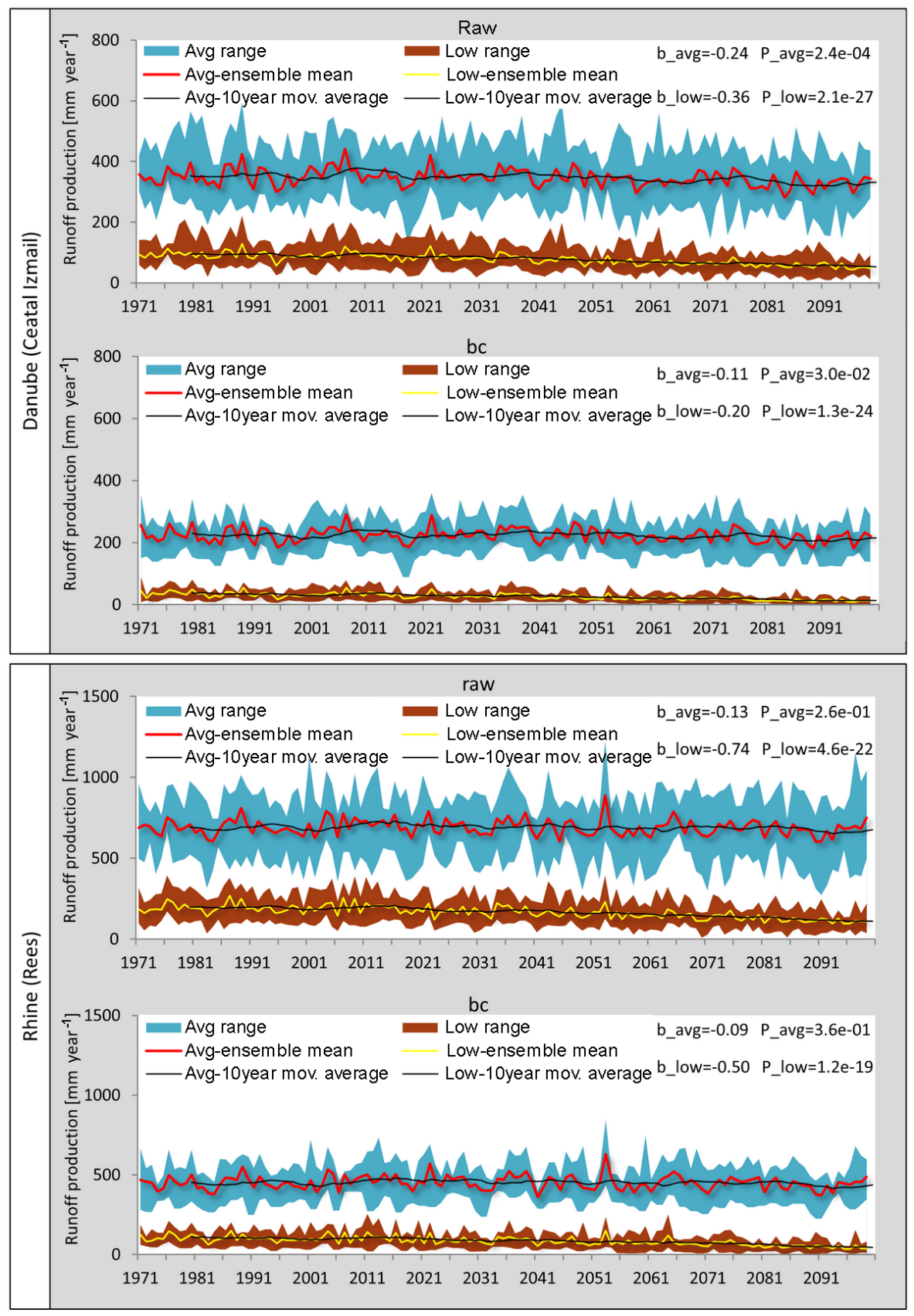

Figure 6.

Guadiana it is difficult to observe a trend in the bias corrected low percentile runoff as the values are already very low. For the raw output however there is an abrupt decrease from 0 to $+2{ }^{\circ} \mathrm{C}$ which continues with a milder trend up to $+4{ }^{\circ} \mathrm{C}$.

Figure 9 illustrates the correlation between the percent projected change in annual average and 10th percentile runoff production from bias corrected and raw forcing, for the +2 and +4 SWLs.

Concerning the effect of bias adjustment, it can be observed that regardless of the significant differences in mag- nitude between runoff from raw and bias corrected data discussed before, the projected change in average flow by the two forcings almost coincides for the $+2 \mathrm{SWL}$. For the +4 SWL the GCM range has increased for Kemijoki after bias adjustment, while for the rest of the basins raw and bias corrected data result in very similar levels of same percent change. For the projected change in 10th percentile runoff, the larger spreading of the values in Fig. 9 (right column panels) shows that the GCM uncertainty in this field is higher. The Guadiana is the only basin where bias corrected data re- 

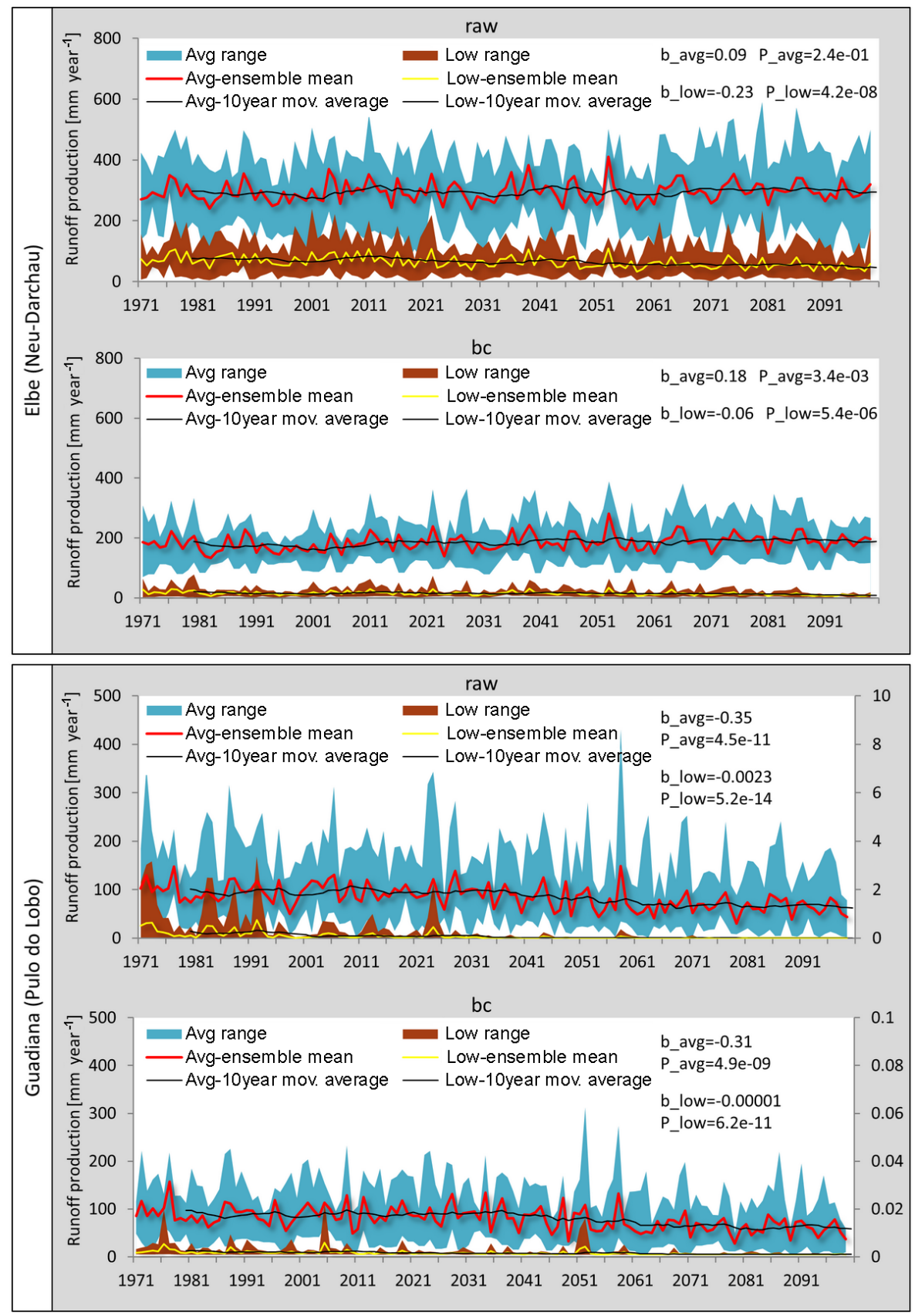

Figure 6.

sult in an improvement in GCM agreement, probably due to its very low values of 10th percentile runoff. Kemijoki is not included in the 10th percentile scatterplots as its projected increase far exceeds the $100 \%$ limit selected. For the rest of the basins, the effect of the bias correction on the change of the 10th percentile runoff is not constant. For the Guadiana and Elbe bias adjustment mostly increases percent change, while for the Rhine and Danube percent change is in general terms decreased after bias correction.
Comparing the difference on percent projected change in average annual runoff from +2 to +4 SWL, it can be observed that temperature increase results in a slight decline in percent change for basins with small absolute values of change, causing sign changes for the Danube and Rhine, and it intensifies the negative and positive changes of the Guadiana and Kemijoki respectively. For the 10th percentile runoff there is a similar response to temperature increase. For the Elbe there is a positive percent change at +2 SWL which falls below zero at +4 SWL, while for the Danube, Rhine and 


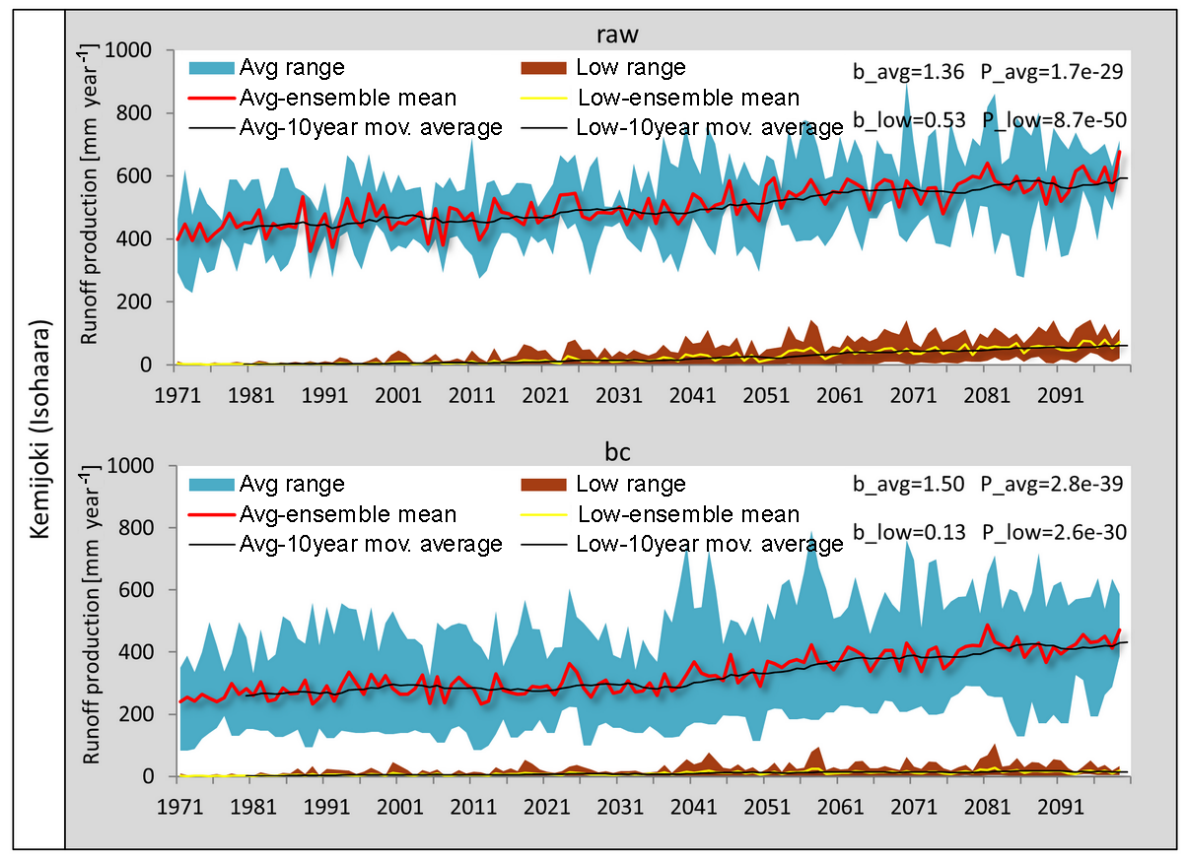

Figure 6. Annual time series of basin averaged runoff production (average and 10th percentile of annual runoff) for raw and bias adjusted Euro-CORDEX data. For both average and 10th percentile time series, the ensemble range, mean and 10-year moving average is shown.

Guadiana the already declining projected changes present are further intensified.

\subsection{Effect of observational data sets for bias correction on the output of the hydrological model}

The aspect of the impact posed by the observational data set used for bias correction to the results of the hydrological simulations is introduced in this part of our analysis. Additional model runs performed with bias adjusted Euro-CORDEX precipitation and temperature, corrected against the E-OBS (instead of the WFDEI) data set, participate in a comprehensive comparison between all the outputs used in this study. The results are illustrated in Fig. 10. Three different sets of outputs are compared: one driven by raw downscaled and two driven by Euro-CORDEX data bias corrected against two different data sets. The comparison considers both the mean and range of the ensembles and results are presented as basin aggregates. The first part of the comparison concerns the longterm annual average for the period 1976 to 2005 (Fig. 10, top row panels) and apart from the model results includes values corresponding to observations, derived from GRDC discharge measurements. Observations can serve as a baseline for this comparison, allowing us to evaluate which configuration can better simulate "true" water budget numbers and the effect of bias correction with respect to this baseline.

For all basins the raw data result in overestimates of runoff production, which is though significantly reduced after bias correction. E-OBS corrected data however produce values lower than the observations (with the exception of the Guadiana), while the WFDEI-corrected data produce the best simulation in terms of approximating the observed values. From Figs. S1 and S2 of the Supplement (showing the effect of bias correction on the forcing variables of precipitation and temperature) it can be deduced that E-OBS corrected precipitation has lower values than precipitation adjusted against the WFDEI data set. This explains the lower runoff produced by the E-OBS bias adjusted data set, as it is reasonable for the differences in precipitation to reflect on the output of the hydrological model. As has already been revealed in previous stages of this analysis, the positive impact that bias adjustment has on the increase of model agreement is again clear. The only exception is Kemijoki basin due to its high latitude position (the coefficient of variation was increased after bias correction for the high latitude areas).

Changes in annual average runoff production at the +4 SWL appear to be more intensified compared to the +2 SWL (Fig. 10, middle and bottom panels). Although for percent change the differences of the distinctive configurations are less pronounced, variations can be observed between the two bias corrected data driven simulations. It is also interesting that the effect of bias correction on reducing the uncertainty is not that strong when looking the results from the more statistical perspective of percent projected change. The improvements in model agreement after 
Table 2. Basin's annual average runoff production for raw and bias adjusted Euro-CORDEX data.

\begin{tabular}{|c|c|c|c|c|c|c|c|c|c|c|c|c|}
\hline \multicolumn{13}{|c|}{ Basin's annual average runoff production $\left(\mathrm{mm} \mathrm{yr}^{-1}\right)$} \\
\hline & \multicolumn{6}{|c|}{ Raw } & \multicolumn{6}{|c|}{ Bias corrected } \\
\hline & \multicolumn{6}{|c|}{ Historical average 1976-2005 } & \multicolumn{6}{|c|}{ Historical average 1976-2005 } \\
\hline Danube & 462.05 & 362.35 & 383.78 & 304.02 & 266.21 & 355.68 & 219.37 & 249.80 & 201.95 & 226.70 & 229.00 & 225.36 \\
\hline Rhine & 794.21 & 845.83 & 616.94 & 710.16 & 495.99 & 692.63 & 426.67 & 503.68 & 415.00 & 439.11 & 470.29 & 450.95 \\
\hline Elbe & 371.88 & 356.72 & 219.68 & 337.42 & 174.41 & 292.02 & 148.70 & 203.39 & 135.98 & 174.79 & 202.12 & 173.00 \\
\hline Guadiana & 166.13 & 71.44 & 116.14 & 46.60 & 81.51 & 96.36 & 93.14 & 96.42 & 90.06 & 79.22 & 89.82 & 89.73 \\
\hline Kemijoki & 428.17 & 482.28 & 427.95 & 418.03 & 507.48 & 452.78 & 174.68 & 327.78 & 197.30 & 238.28 & 450.70 & 277.75 \\
\hline \multirow[t]{2}{*}{ 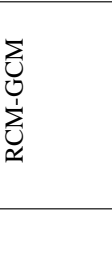 } & $\begin{array}{r}\text { RCA4- } \\
\text { GFDL- } \\
\text { ESM2M } \\
+3.2 \\
(2071- \\
2100)\end{array}$ & $\begin{array}{r}\text { RCA4- } \\
\text { NorESM1 } \\
+3.75 \\
(2071- \\
2100)\end{array}$ & $\begin{array}{r}\text { RCA4- } \\
\text { MIROC } \\
5+3.76 \\
(2071- \\
2100)\end{array}$ & $\begin{array}{r}\text { RCA4- } \\
\text { IPSL- } \\
\text { CM5A } \\
+4 \\
(2055- \\
2084)\end{array}$ & $\begin{array}{r}\text { RCA4- } \\
\text { HadGEM2- } \\
\text { ES +4 } \\
(2060- \\
2089)\end{array}$ & Mean & $\begin{array}{r}\text { RCA4- } \\
\text { GFDL- } \\
\text { ESM2M } \\
+3.2 \\
(2071- \\
2100)\end{array}$ & $\begin{array}{r}\text { RCA4- } \\
\text { NorESM1 } \\
+3.75 \\
(2071- \\
2100)\end{array}$ & $\begin{array}{r}\text { RCA4- } \\
\text { MIROC } \\
5+3.76 \\
(2071- \\
2100)\end{array}$ & $\begin{array}{r}\text { RCA4- } \\
\text { IPSL- } \\
\text { CM5A } \\
+4 \\
(2055- \\
2084)\end{array}$ & $\begin{array}{r}\text { RCA4- } \\
\text { HadGEM2- } \\
\text { ES +4 } \\
(2060- \\
2089)\end{array}$ & Mean \\
\hline & \multicolumn{6}{|c|}{ Absolute change from baseline in the projected time slice } & \multicolumn{6}{|c|}{ Absolute change from baseline in the projected time slice } \\
\hline Danube & -54.57 & 3.36 & -13.20 & -42.04 & -14.96 & -24.28 & -11.83 & -1.38 & 3.61 & -30.04 & -11.48 & -10.22 \\
\hline Rhine & 59.95 & -19.81 & -13.23 & -39.31 & -20.14 & -6.51 & 53.83 & -5.91 & 6.09 & -44.17 & -21.73 & -2.37 \\
\hline Elbe & 2.05 & 33.91 & 30.00 & -28.39 & 19.05 & 11.32 & 22.81 & 33.28 & 31.55 & -5.57 & 25.71 & 21.55 \\
\hline Guadiana & -55.70 & -37.02 & -17.16 & -14.09 & -46.16 & -34.03 & -26.23 & -48.81 & -10.37 & -28.52 & -45.23 & -31.83 \\
\hline \multirow[t]{2}{*}{ Kemijoki } & 146.86 & 67.46 & 67.48 & 174.94 & 108.26 & 113.00 & 149.69 & 97.38 & 89.71 & 179.15 & 119.97 & 127.18 \\
\hline & \multicolumn{6}{|c|}{ Percent change from baseline in the projected time slice } & \multicolumn{6}{|c|}{ Percent change from baseline in the projected time slice } \\
\hline Danube & -11.81 & 0.93 & -3.44 & -13.83 & -5.62 & -6.83 & -5.39 & -0.55 & 1.79 & -13.25 & -5.01 & -4.54 \\
\hline Rhine & 7.55 & -2.34 & -2.14 & -5.54 & -4.06 & -0.94 & 12.62 & -1.17 & 1.47 & -10.06 & -4.62 & -0.53 \\
\hline Elbe & 0.55 & 9.51 & 13.66 & -8.42 & 10.92 & 3.88 & 15.34 & 16.36 & 23.20 & -3.19 & 12.72 & 12.46 \\
\hline Guadiana & -33.53 & -51.82 & -14.78 & -30.24 & -56.63 & -35.31 & -28.16 & -50.63 & -11.51 & -36.00 & -50.35 & -35.47 \\
\hline Kemijoki & 34.30 & 13.99 & 15.77 & 41.85 & 21.33 & 24.96 & 85.69 & 29.71 & 45.47 & 75.19 & 26.62 & 45.79 \\
\hline
\end{tabular}

Table 3. Basin's 10th percentile of runoff production, derived on an annual basis, for raw and bias adjusted Euro-CORDEX data.

\begin{tabular}{|c|c|c|c|c|c|c|c|c|c|c|c|c|}
\hline \multicolumn{13}{|c|}{ Basin's 10th percentile on annual basis $\left(\mathrm{mm} \mathrm{yr}^{-1}\right)$} \\
\hline & \multicolumn{6}{|c|}{ Raw } & \multicolumn{6}{|c|}{ Bias corrected } \\
\hline & \multicolumn{6}{|c|}{ Historical average 1976-2005 } & \multicolumn{6}{|c|}{ Historical average 1976-2005 } \\
\hline Danube & 146.63 & 96.81 & 80.55 & 79.71 & 58.69 & 92.48 & 31.49 & 41.73 & 28.54 & 30.32 & 37.94 & 34.00 \\
\hline Rhine & 250.22 & 258.37 & 162.58 & 200.59 & 109.23 & 196.20 & 98.23 & 120.41 & 93.24 & 101.58 & 107.68 & 104.23 \\
\hline Elbe & 118.79 & 99.15 & 29.98 & 98.30 & 28.95 & 75.04 & 10.22 & 20.08 & 11.23 & 16.75 & 22.14 & 16.08 \\
\hline Guadiana & 0.74 & 0.00 & 0.12 & 0.00 & 0.00 & 0.17 & 0.00 & 0.00 & 0.00 & 0.00 & 0.00 & 0.00 \\
\hline Kemijoki & 0.80 & 4.50 & 1.10 & 1.47 & 10.79 & 3.73 & 0.25 & 5.91 & 0.53 & 1.00 & 11.60 & 3.86 \\
\hline \multirow[t]{2}{*}{$\sum_{\substack{1 \\
\sum_{1}^{1}}}$} & $\begin{array}{r}\text { RCA4- } \\
\text { GFDL- } \\
\text { ESM2M } \\
+3.2 \\
(2071- \\
2100)\end{array}$ & $\begin{array}{r}\text { RCA4- } \\
\text { NorESM1 } \\
+3.75 \\
(2071- \\
2100)\end{array}$ & $\begin{array}{r}\text { RCA4- } \\
\text { MIROC } \\
5+3.76 \\
(2071- \\
2100)\end{array}$ & $\begin{array}{r}\text { RCA4- } \\
\text { IPSL- } \\
\text { CM5A } \\
+4 \\
(2055- \\
2084)\end{array}$ & $\begin{array}{r}\text { RCA4- } \\
\text { HadGEM2- } \\
\text { ES +4 } \\
(2060- \\
2089)\end{array}$ & Mean & $\begin{array}{r}\text { RCA4- } \\
\text { GFDL- } \\
\text { ESM2M } \\
+3.2 \\
(2071- \\
2100)\end{array}$ & $\begin{array}{r}\text { RCA4- } \\
\text { NorESM1 } \\
+3.75 \\
(2071- \\
2100)\end{array}$ & $\begin{array}{r}\text { RCA4- } \\
\text { MIROC } \\
5+3.76 \\
(2071- \\
2100)\end{array}$ & $\begin{array}{r}\text { RCA4- } \\
\text { IPSL- } \\
\text { CM5A } \\
+4 \\
(2055- \\
2084)\end{array}$ & $\begin{array}{r}\text { RCA4- } \\
\text { HadGEM2- } \\
\text { ES +4 } \\
(2060- \\
2089)\end{array}$ & Mean \\
\hline & \multicolumn{6}{|c|}{ Absolute change from baseline in the projected time slice } & \multicolumn{6}{|c|}{ Absolute change from baseline in the projected time slice } \\
\hline Danube & -53.89 & -23.89 & -18.83 & -38.22 & -27.41 & -32.45 & -18.03 & -15.89 & -9.68 & -22.28 & -24.37 & -18.05 \\
\hline Rhine & -89.38 & -87.03 & -20.39 & -103.94 & -43.25 & -68.80 & -31.43 & -49.93 & -19.49 & -69.92 & -52.57 & -44.67 \\
\hline Elbe & -29.14 & -21.01 & 1.21 & -44.80 & -9.96 & -20.74 & -2.03 & -2.73 & -0.91 & -8.90 & -8.52 & -4.62 \\
\hline Guadiana & -0.73 & 0.00 & -0.11 & 0.00 & 0.00 & -0.17 & 0.00 & 0.00 & 0.00 & 0.00 & 0.00 & 0.00 \\
\hline \multirow[t]{2}{*}{ Kemijoki } & 16.77 & 53.16 & 36.71 & 56.80 & 72.44 & 47.18 & 3.24 & 3.12 & 5.05 & 22.55 & 16.79 & 10.15 \\
\hline & \multicolumn{6}{|c|}{ Percent change from baseline in the projected time slice } & \multicolumn{6}{|c|}{ Percent change from baseline in the projected time slice } \\
\hline Danube & -36.75 & -24.68 & -23.38 & -47.95 & -46.71 & -35.09 & -57.26 & -38.07 & -33.90 & -73.50 & -64.22 & -53.08 \\
\hline Rhine & -35.72 & -33.68 & -12.54 & -51.82 & -39.59 & -35.07 & -32.00 & -41.46 & -20.91 & -68.83 & -48.82 & -42.86 \\
\hline Elbe & -24.53 & -21.19 & 4.04 & -45.57 & -34.41 & -27.64 & -19.86 & -13.58 & -8.11 & -53.15 & -38.47 & -28.71 \\
\hline Guadiana & -98.67 & -73.37 & -96.24 & -26.22 & -76.38 & -98.01 & -48.53 & -50.67 & -65.42 & -32.31 & -56.63 & -53.36 \\
\hline Kemijoki & 2088.40 & 1181.25 & 3328.72 & 3877.01 & 671.51 & 1264.16 & 1283.66 & 52.88 & 946.08 & 2265.11 & 144.71 & 263.09 \\
\hline
\end{tabular}




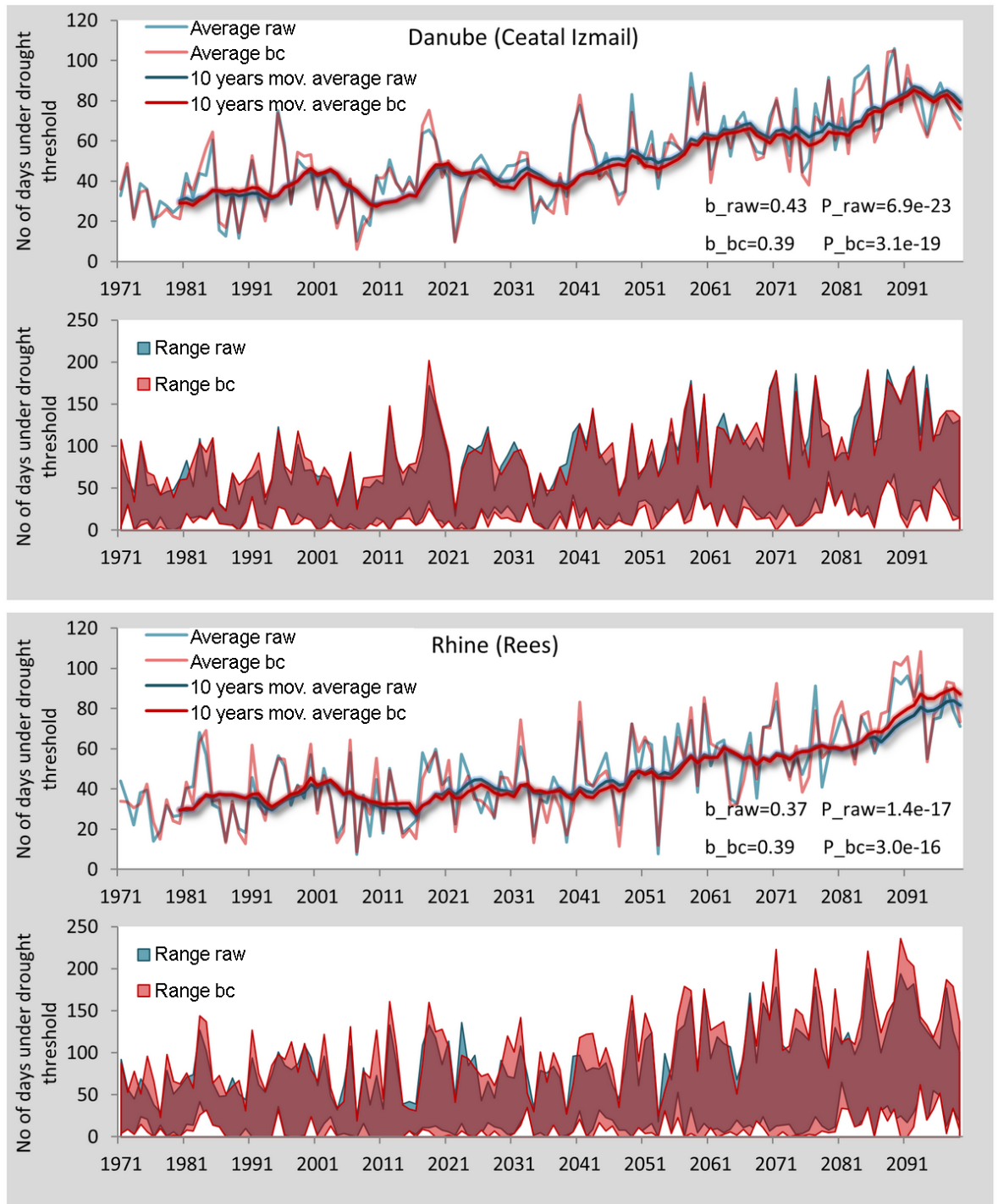

Figure 7.

bias adjustment however are still pronounced for all basins except for the Rhine.

From the application of the same analysis to 10th percentile runoff production (Fig. S6), it is deduced that for the low flows the E-OBS corrected data again produce lower values of runoff compared to WFDEI. In this case, however, even the raw forced output (which is wetter than the bias corrected) underestimates the observed 10th percentile runoff values. Regarding the percent projected changes, results from bias corrected data produce smaller values compared to the raw data, while E-OBS adjusted data result in decreased changes compared to output from WFDEI adjusted forcing.

\section{Discussion}

\subsection{Hydrological response to $+4^{\circ} \mathrm{C}$ global warming}

In our analysis we investigated the effects of climate change on the European hydrological resources, extracting time periods that correspond to an increase of $4{ }^{\circ} \mathrm{C}$ in the global temperature, rather than using pre-defined time slices. The same approach was followed by Vautard et al. (2013), stating that reduced GCM induced uncertainty is achieved with this method, and thus the regional patterns of change in the variables of study are strengthened.

In our study only one impact model (JULES) was used. Hagemann et al. (2013) argue that impact model induced uncertainty in future hydrological simulations is larger than that of the GCMS for some regions of the land surface and sug- 


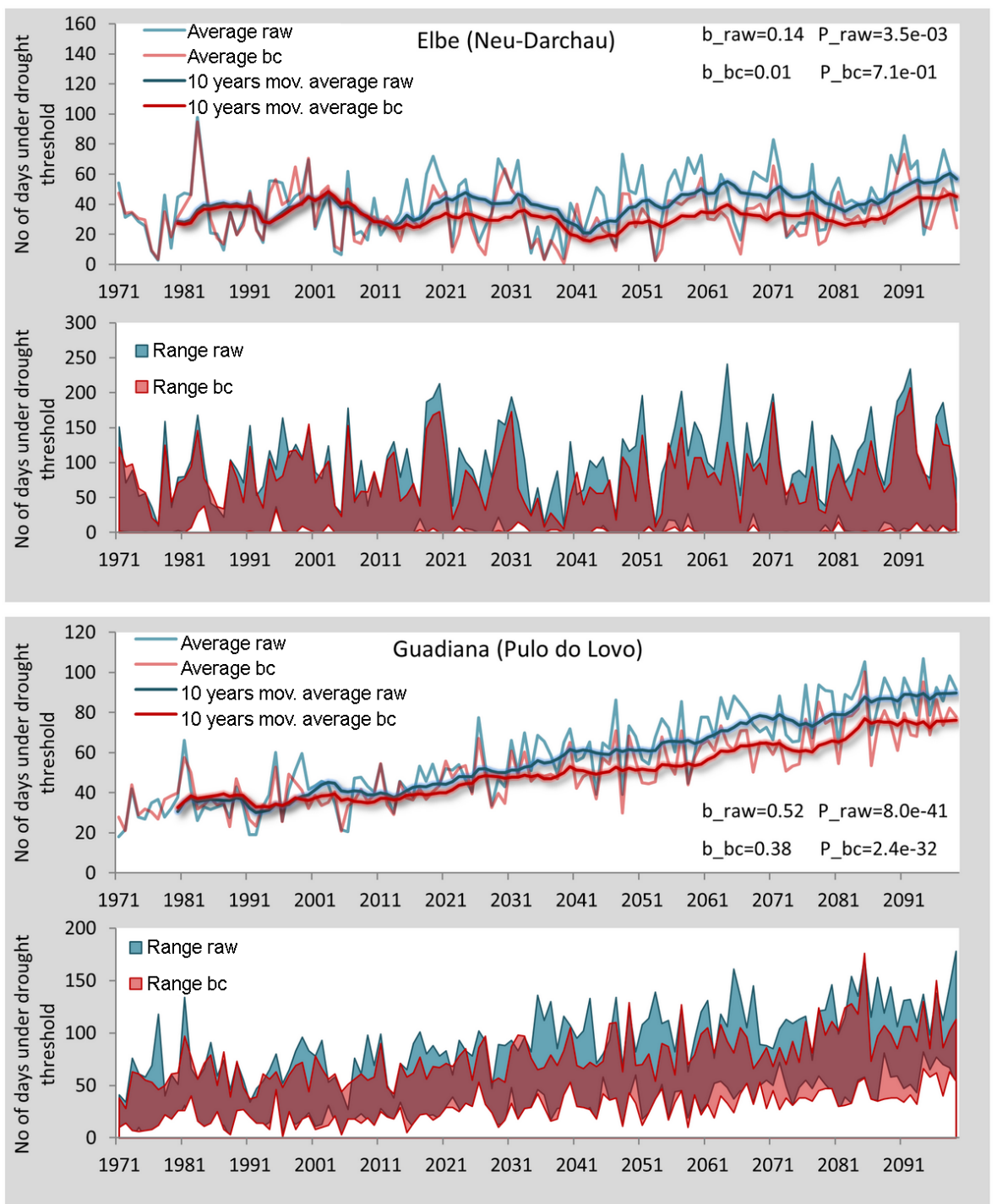

Figure 7.

gest using multi-impact model ensembles to deal with this issue. However useful conclusions can be drawn also from studies employing a single GHM/LSM. Examples of such single model climate change impact assessments performed recently are the studies of Schneider et al. (2013) and Laizé et al. (2013) with the WaterGAP GHM, the studies of Arnell and Gosling (2013), Gosling and Arnell (2013) and Arnell et al. (2013) with the GHM MacPDM and of Hanasaki et al. (2010) using the H08 LSM.

The findings of the study regarding the climate changed induced alterations of the mean hydrological state in Europe show decreasing trends for southern Europe, including the Mediterranean region, and strong increasing trends for northern and north-eastern Europe. These follow the same patterns as identified by previous studies. Schneider et al. (2013) found that the most pronounced changes in the magnitude of European river flows are projected for the Mediterranean region and the northern part of the continent. Hagemann et al. (2013) reported positive changes in projected runoff for the high latitudes and negative changes for southern Europe. For central Europe the projected changes are smaller (mostly in the range of -25 to $25 \%$ ) and thus more easily obscured by GCM and bias correction uncertainty. Arnell and LloydHughes (2014) report that the main source of uncertainty in the projected climate impact stems from the GCMs, with a range of uncertainty for the CMIP5 ensemble that is similar to that of older climate model experiments.

The projected relative changes found for 10th percentile runoff are far more pronounced than the changes in average, even for the regions where changes in average-state annual runoff were negligible. This finding implies that seasonality in runoff is likely to intensify under climate change and 


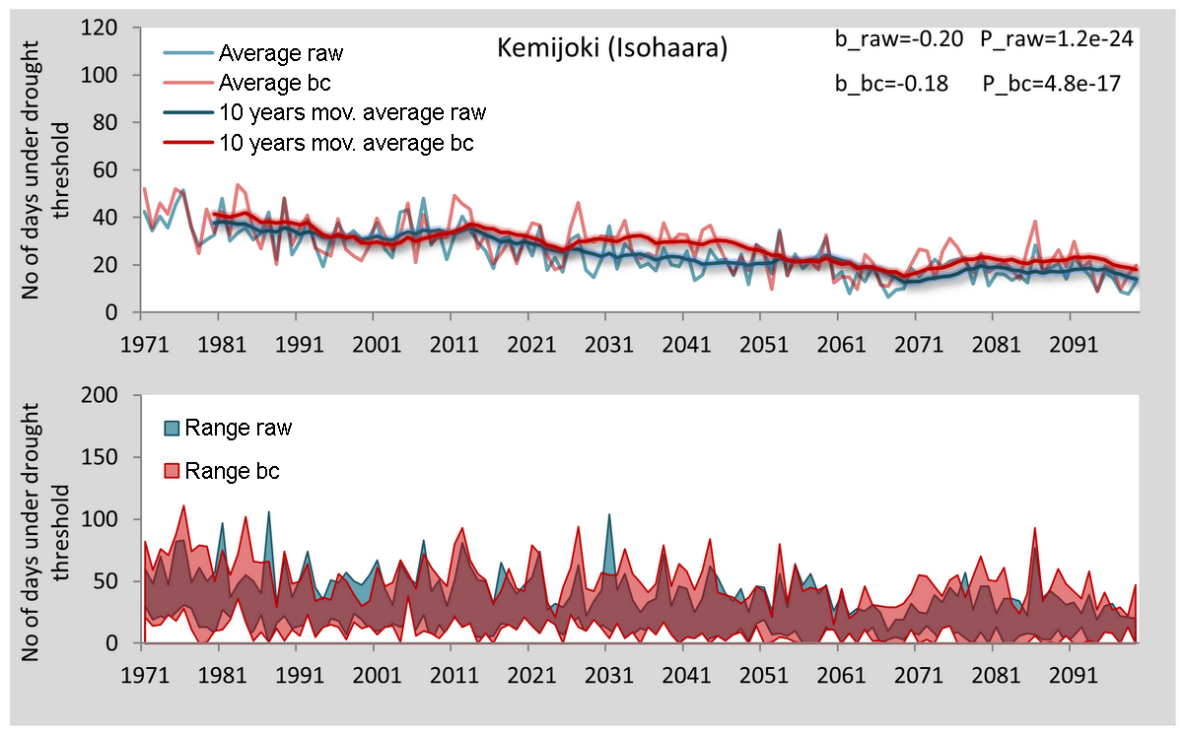

Figure 7. Number of days under drought threshold per year for raw and bias adjusted Euro-CORDEX data. Ensemble mean and 10-year moving average of the ensemble mean (top panel) and ensemble range (bottom panel).

is in accordance with the results of Fung et al. (2011) and Van Vliet et al. (2013) who also reported pronounced seasonality in their projected simulations. This may translate to increased dry spells and thus elevated drought risks in the future. Under the light of these findings (mean-state runoff changing slightly and low-state changing significantly), more extreme hydrological droughts are expected in the future. It should be noted however that projections of low flow bear higher uncertainty compared to average-state, as indicated by the higher values of the coefficient of variation. Similar results of increased model spread expressed as cv for low flows compared to average state flows were found by Koirala et al. (2014).

Specifically for the Guadiana River, the close to zero values of 10th percentile runoff encountered even in the historical period indicate that the river exhibits an intermittent flow regime. This is relevant for this particular river, as it is located in a semi-arid region and intermittent flows typically characterise its hydrological regime (Collares-Pereira et al., 2000; Filipe et al., 2002; Pires et al., 1999). Given the changes that are projected for the Iberian Peninsula at $+4 \mathrm{SWL}$, it is expected that the intermittent flow regime in the Guadiana might intensify.

Concerning the effects of a $+4{ }^{\circ} \mathrm{C}$ temperature increase on the European hydrological regime compared to a $+2{ }^{\circ} \mathrm{C}$ increase, significant alterations posed by the $+2^{\circ}$ of global warming are identified for south Europe and northern and north-eastern Europe, where the respective decreasing and rising trends are intensified. Fung et al. (2011) also found that changes in mean annual runoff identified at +2 are intensified at +4 . More specifically, their study reports that regions where decreasing runoff trends have been found be- come even drier and, in contrast, areas where runoff is projected to increase are getting wetter. For most of the river basins examined by Fung et al. (2011), water stress is increased at +4 compared to +2 , with the exception of a few basins where an increase in rainfall is projected thus decreasing water stress. In our study, the basins located at central Europe (Danube, Rhine and Elbe) do not exhibit significant changes in their annual average runoff values due to temperature increase from +2 to +4 . For 10th percentile runoff, however, a temperature increase of $+4^{\circ} \mathrm{C}$ from the pre-industrial baseline results in an aggravation of the lowering trends that are already significantly affecting the low runoff regime at $+2{ }^{\circ} \mathrm{C}$.

Our analysis of drought climatology at the basin scale was based on the total number of days under a predefined daily varying drought threshold. We did not employ any buffering criterion for the days under threshold to be accounted for in the total sum (as discussed for example by Sung and Chung, 2014, and Tallaksen et al., 1997). The use of such a criterion would have decreased the calculated dry days. However, as the interpretation of the results of this study is mostly oriented towards identifying trends of change rather than absolute numbers describing the future regime, the lack of a buffering criterion is not supposed to notably affect the extracted conclusions. Wanders et al. (2015) employed a transient variable threshold for the assessment of the drought conditions under climate change, considering a gradual adaptation of the ecosystem on the altered hydrological regime. This is an interesting alternative, especially for climate change mitigation and adaptation studies. In our study we aimed to identify global warming induced changes in the future hydrological state without considering adapta- 


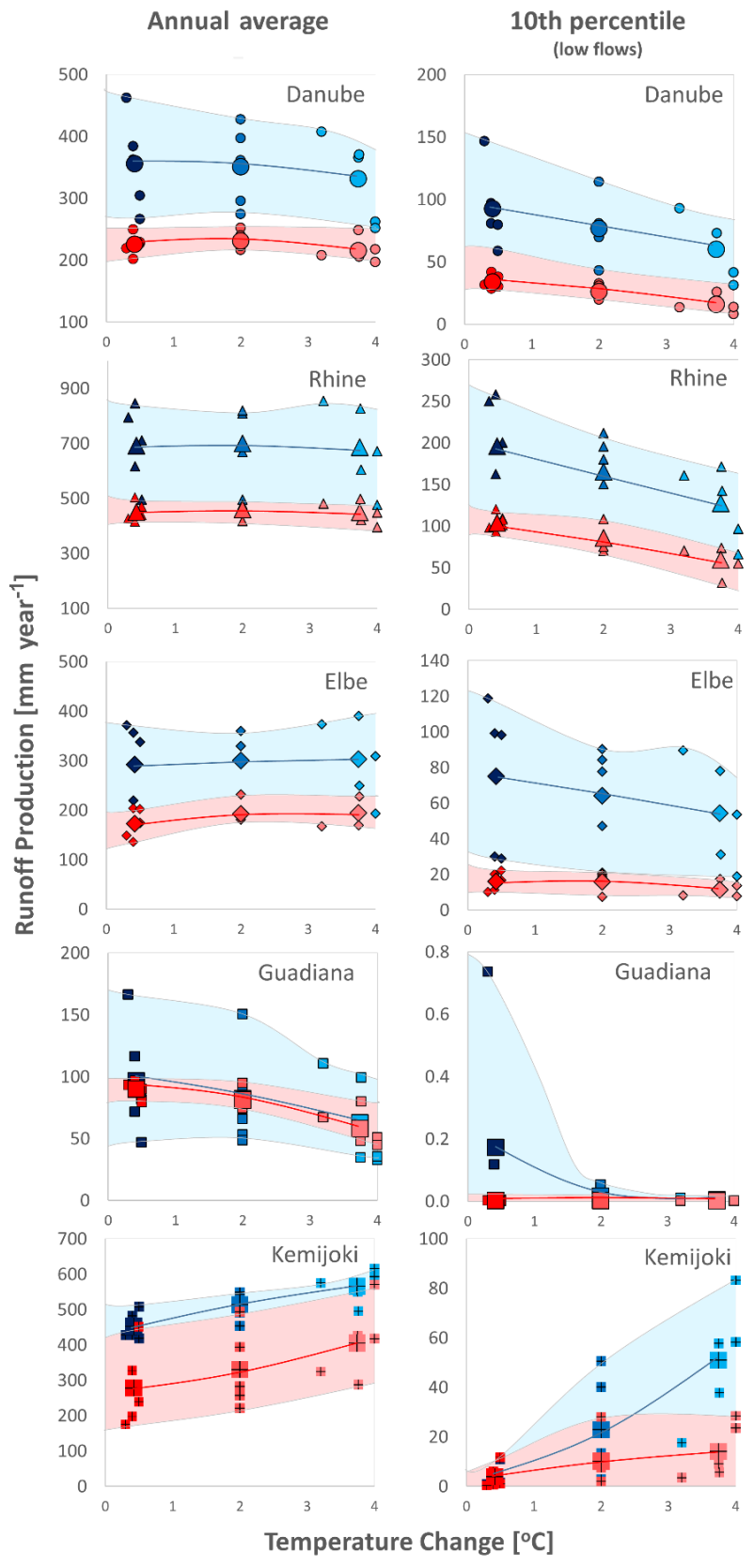

Figure 8. Variation of runoff production with respect to temperature change (+2 and +4 SWLs) for raw (light blue) and bias adjusted (light red) Euro-CORDEX data, for both annual average (left column panels) and 10th percentile (right column panels) runoff production. Small markers represent the value of each individual model and bigger markers correspond to ensemble mean value.

tion; thus, the same historically derived threshold was applied to the whole length of the simulated runoff time series.

From the analysis performed on drought climatology, an increased number of days per year under the historically defined drought threshold is found for the basins of the Danube, Rhine and Guadiana. Our results correspond with the find-

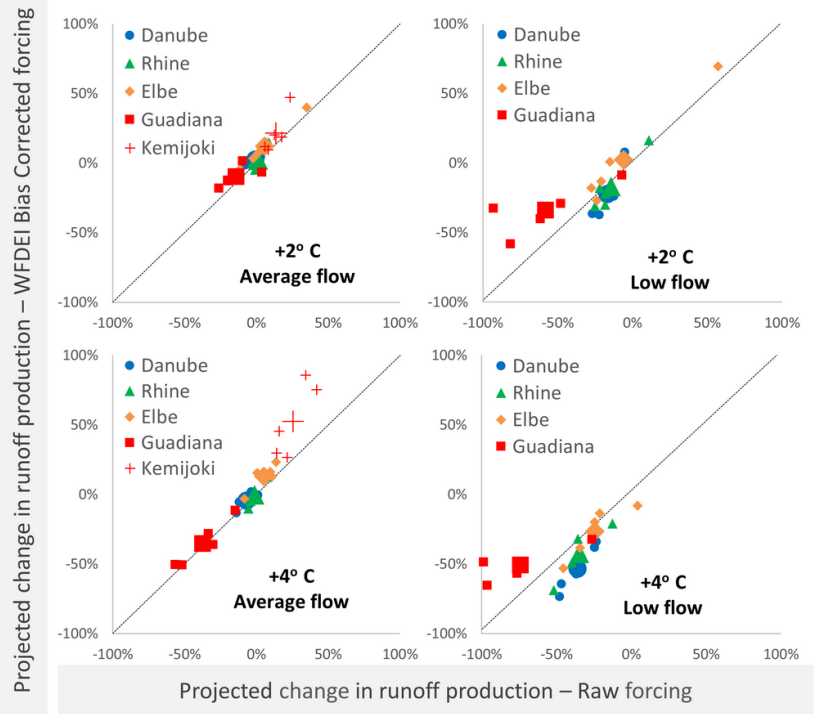

Figure 9. Correlation between projected change in basin averaged runoff production derived from WFDEI-bias adjusted and raw Euro-CORDEX data, for both annual average (left panels) and 10th percentile (right panels) runoff production. Correlation is examined at $+2{ }^{\circ} \mathrm{C} \mathrm{SWL}$ (top panels) and at $+4{ }^{\circ} \mathrm{C} \mathrm{SWL}$ (bottom panels). Small markers represent the value of each individual model and bigger markers correspond to ensemble mean value.

ings of previous studies about drought regime under climate change. Giuntoli et al. (2015), investigating future high and low flow regimes at the global scale, using multiple impact models and climate scenarios, found increased number of low flow days in southern Europe. In the study of Wanders and Van Lanen (2015) the impact of climate change on the hydrological drought regime of different climate regions was assessed, using a conceptual hydrological model forced with three GCMs. The study findings describe a decrease in the frequency of drought events in the future, which however does not point towards drought alleviation. In contrast, it relates to increased drought event duration and deficit volume. These effects are more pronounced for the arid climates that already face problems of water availability.

\subsection{The effect of bias correction}

As proposed by Ehret et al. (2012), both raw and bias corrected data driven simulations are presented in our study, in order to comprehensively assess the effect of bias correction on our results. In four of the five study basins, raw data driven simulated runoff overestimates the corresponding observed values. After bias correction, the modelled results represent more accurately the past hydrological regime. Similar improvements in the bias corrected output have been reported by Hagemann et al. (2011), Muerth et al. (2013) and Harding et al. (2014). 


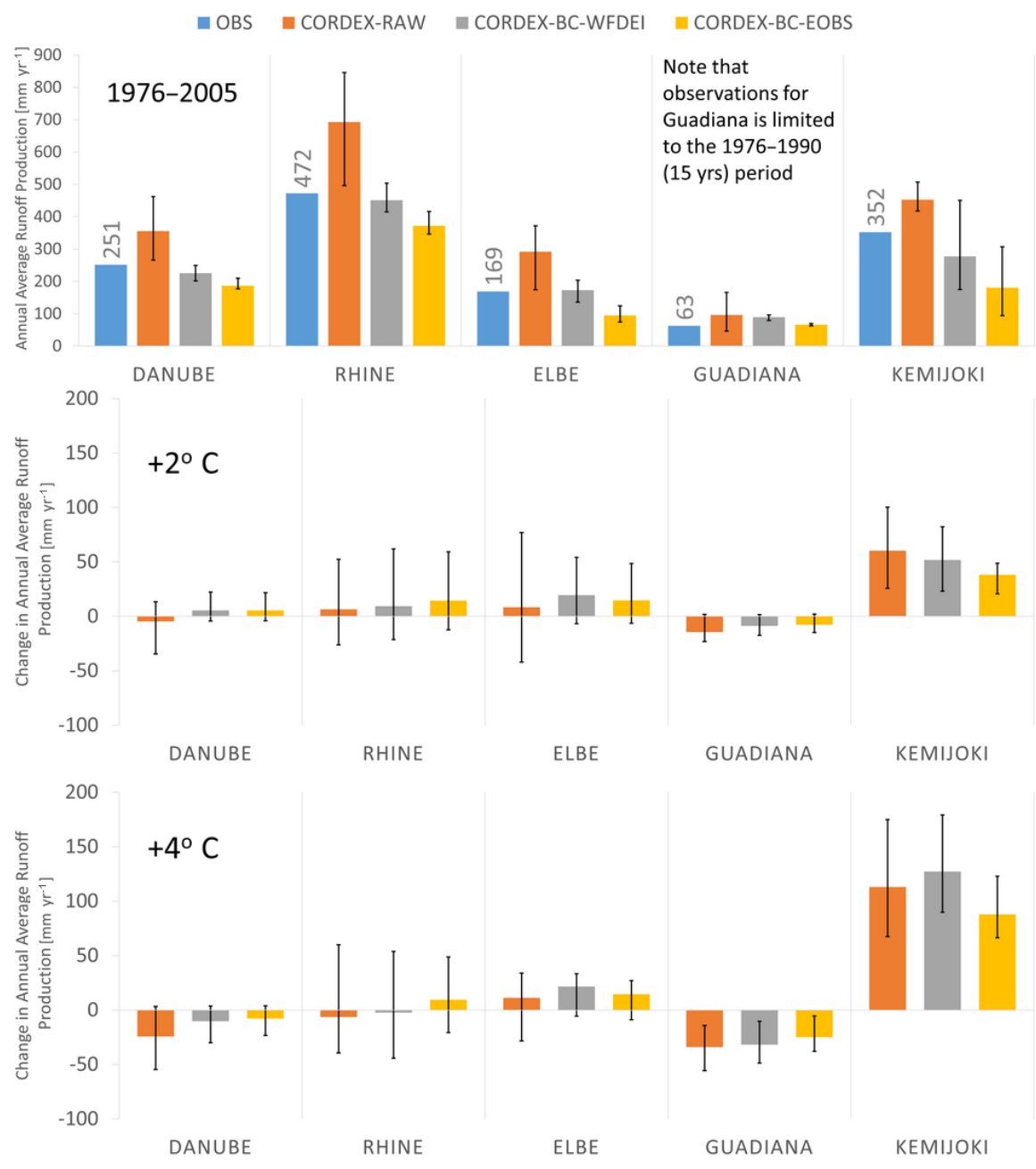

Figure 10. Comparison between the simulations of raw Euro-CORDEX data and bias adjusted against two different data sets (WFDEI and E-OBS) for five study basins. Bars show the ensemble means and error bars the minimum and maximum ensemble member values. Top row panels: annual average runoff production for the period 1976 to 2005 . OBS values are derived from GRDC discharge measurements converted to basin averages at the annual timescale. Middle row panels: percent change in annual average runoff production at the $+2 \mathrm{SWL}$; and bottom row panels: at the $+4 \mathrm{SWL}$.

For some regions, the sign of the projected change in runoff shifted after bias correction. This finding was also encountered in the study of Hagemann et al. (2011). Hagemann et al. (2011) underline that these changes in the climate signal reveal another uncertainty aspect of the GCM to GHM modelling procedure, that is inherent to the GCM but becomes apparent after the bias adjustment of the climate model output. Teng et al. (2015) argue that signal changes are produced by bias correction errors in higher percentiles' precipitation, thus adding another factor to the uncertainty of the runoff projections.

Although the absolute values of raw and bias corrected simulations differ significantly, this does not apply to the projected relative changes. Liu et al. (2014) also found that raw and bias corrected data resulted in similar estimations of relative changes for a series of variables, including ET and runoff. The study of Muerth et al. (2013) investigates the effect of bias adjustment on hydrological simulations and their climate change induced alterations. Concerning the relative changes between baseline and future time slices, it is reported that bias correction does not influence notably the hydrologic indicators, apart from the one describing flow seasonality.

Chen et al. (2011) identify three uncertainty components in bias correction applications: the uncertainty of the different GCMs, the variable emission scenarios and that of the decade used for bias adjustment. A comparison of the latter uncertainty source with the two former concluded that the choice of correction decade has the smallest contribution to total uncertainty. In this paper we address another uncertainty source: that of the data set used for correction. It was found that the WFDEI bias corrected simulation captured better the past hydrological regime compared to the E-OBS bias cor- 
rected configuration. The differences between the two simulations abate when results are expressed as percent change but their variations are still of the same magnitude as that between raw and bias corrected data. This implies that the selection of the observational data set used for bias correction is not a trivial step of the modelling procedure, and it should be treated as an extra factor that causes the uncertainty window of the projected hydrologic conditions to further open.

\section{Conclusions}

In this paper, the future mean- and low-hydrological states under $+4{ }^{\circ} \mathrm{C}$ of global warming were assessed for the European region, using the novel data set of the Euro-CORDEX climate projections. An analysis of the changes in future drought climatology was performed for five major European basins and the impact of $+2{ }^{\circ} \mathrm{C}$ versus $+4^{\circ} \mathrm{C}$ global warming was estimated. Concurrently, the effect of bias correction of the climate model outputs on the projected climate was also evaluated.

The concluding remarks of this study are summarised below.

Projections show an intensification of the water cycle at +4 SWL, as even for areas where the average state is not considerably affected, there are remarkable projected decreases of low flows. With the exception of the Scandinavian Peninsula and some small areas in central Europe, 10th percentile runoff production is projected to reduce all over Europe. This favours the formation of extreme hydrological events, thus more droughts compared to the current state could be expected in the future due to the warming climate.

Drought climatology is projected to change to more dry days per year for the Danube, Rhine and Guadiana basins. Thus these areas are projected to experience more usual and more intense drought events in the future.

For the areas where clear decreasing or increasing runoff trends are identified in the projections, these changes are considerably intensified when moving from the +2 to +4 SWL. Decreasing trends apply to southern Europe, including the Mediterranean region, while strong increasing trends are projected for northern and north-eastern Europe. For the rest of the European region where trends are not clear or ensemble members do not agree towards the change, the effect of the further warming from +2 to +4 SWL, does not seem to severely affect the hydrological state, which is however already significantly altered at +2 SWL compared to preindustrial.

Bias correction results in an improved representation of the historical hydrological conditions. However, raw and bias corrected simulations exhibit minor variations for results of statistical interpretation (in our study: percent change, number of days under drought threshold).

The data set used for bias correction can affect the quality of the projections in absolute terms to a great extent.
The comparison performed here showed that the WFDEIcorrected data set produces simulations that capture better the past observed hydrologic state compared to the E-OBScorrected data set, and should thus be preferred for bias correction applications over Europe. The selection of the "correct" data set is an added uncertainty to the climate impact modelling chain, with magnitude similar to that of the bias correction procedure itself.

\section{The Supplement related to this article is available online at doi:10.5194/hess-20-1785-2016-supplement.}

Acknowledgements. The research leading to these results has received funding from the HELIX project of the European Union's Seventh Framework Programme for research, technological development and demonstration under grant agreement no. 603864. We acknowledge the World Climate Research Programme's Working Group on Regional Climate, and the Working Group on Coupled Modelling, former coordinating body of CORDEX and responsible panel for CMIP5. We also thank the climate modelling groups (listed in Table 1 of this paper) for producing and making available their model output. We also acknowledge the Earth System Grid Federation infrastructure, an international effort led by the US Department of Energy's Program for Climate Model Diagnosis and Intercomparison, the European Network for Earth System Modelling and other partners in the Global Organisation for Earth System Science Portals (GO-ESSP). Finally, we acknowledge the E-OBS data set from the ENSEMBLES EU-FP6 project (http://ensembles-eu.metoffice.com) and the data providers in the ECA \& D project (http://www.ecad.eu).

Edited by: M. Werner

\section{References}

Alfieri, L., Burek, P., Feyen, L., and Forzieri, G.: Global warming increases the frequency of river floods in Europe, Hydrol. Earth Syst. Sci., 19, 2247-2260, doi:10.5194/hess-19-22472015, 2015.

Andrews, T., Gregory, J. M., Webb, M. J., and Taylor, K. E.: Forcing, feedbacks and climate sensitivity in CMIP5 coupled atmosphere-ocean climate models, Geophys. Res. Lett., 39, 17, doi:10.1029/2012GL051607, 2012.

Arnell, N. W. and Gosling, S. N.: The impacts of climate change on river flow regimes at the global scale, J. Hydrol., 486, 351-364, doi:10.1016/j.jhydrol.2013.02.010, 2013.

Arnell, N. W. and Lloyd-Hughes, B.: The global-scale impacts of climate change on water resources and flooding under new climate and socio-economic scenarios, Climatc Change, 122, 127140, doi:10.1007/s10584-013-0948-4, 2014.

Arnell, N. W., Lowe, J. A., Brown, S., Gosling, S. N., Gottschalk, P., Hinkel, J., Lloyd-Hughes, B., Nicholls, R. J., Osborn, T. J., Osborne, T. M., Rose, G. A., Smith, P., and Warren, R. F.: A global assessment of the effects of climate policy on the impacts of climate change, Nat. Clim. Change, 3, 512-519, doi:10.1038/nclimate1793, 2013. 
Bakopoulou, C., Bulygina, N., Butler, A., and McIntyre, N.: Sensitivity analysis and parameter identifiability of the land surface model JULES at the point scale in permeable catchments, Proc. of British Hydrological Society National Symposium, Dundee, June 2012.

Best, M. J., Pryor, M., Clark, D. B., Rooney, G. G., Essery, R. L. H., Ménard, C. B., Edwards, J. M., Hendry, M. A., Porson, A., Gedney, N., Mercado, L. M., Sitch, S., Blyth, E., Boucher, O., Cox, P. M., Grimmond, C. S. B., and Harding, R. J.: The Joint UK Land Environment Simulator (JULES), model description Part 1: Energy and water fluxes, Geosci. Model Dev., 4, 677-699, doi:10.5194/gmd-4-677-2011, 2011.

Betts, R. A., Collins, M., Hemming, D. L., Jones, C. D., Lowe, J. A., and Sanderson, M. G.: When could global warming reach $4{ }^{\circ}$ C?, Phil. Trans. Roy. Soc. London A-Math. Phys. Eng. Sci., 369, 67-84, doi:10.1098/rsta.2010.0292, 2011.

Betts, R. A., Golding, N., Gonzalez, P., Gornall, J., Kahana, R., Kay, G., Mitchell, L., and Wiltshire, A.: Climate and land use change impacts on global terrestrial ecosystems and river flows in the HadGEM2-ES Earth system model using the representative concentration pathways, Biogeosciences, 12, 1317-1338, doi:10.5194/bg-12-1317-2015, 2015.

Beven, K. J. and Kirkby, M. J.: A physically based, variable contributing area model of basin hydrology / Un modèle à base physique de zone d'appel variable de l'hydrologie du bassin versant, Hydrol. Sci. Bull., 24, 43-69, doi:10.1080/02626667909491834, 1979.

Blyth, E., Clark, D. B., Ellis, R., Huntingford, C., Los, S., Pryor, M., Best, M., and Sitch, S.: A comprehensive set of benchmark tests for a land surface model of simultaneous fluxes of water and carbon at both the global and seasonal scale, Geosci. Model Dev., 4, 255-269, doi:10.5194/gmd-4-255-2011, 2011.

Bonaccorso, B., Peres, D. J., Cancelliere, A., and Rossi, G.: Large Scale Probabilistic Drought Characterization Over Europe, Water Resour. Manage., 27, 1675-1692, doi:10.1007/s11269-0120177-z, 2013.

Burke, E. J., Dankers, R., Jones, C. D., and Wiltshire, A. J.: A retrospective analysis of pan Arctic permafrost using the JULES land surface model, Clim. Dynam., 41, 1025-1038, doi:10.1007/s00382-012-1648-x, 2013.

Chen, C., Haerter, J. O., Hagemann, S., and Piani, C.: On the contribution of statistical bias correction to the uncertainty in the projected hydrological cycle, Geophys. Res. Lett., 38, 1-6, doi:10.1029/2011GL049318, 2011.

Ciscar, J. C., Feyen, L., Soria, A., Lavalle, C., Raes, F., Perry, M., Nemry, F., Demirel, H., Rozsai, M., Dosio, A., and Donatelli, M.: Climate Impacts in Europe-The JRC PESETA II project, 2014.

Clark, D. B., Mercado, L. M., Sitch, S., Jones, C. D., Gedney, N., Best, M. J., Pryor, M., Rooney, G. G., Essery, R. L. H., Blyth, E., Boucher, O., Harding, R. J., Huntingford, C., and Cox, P. M.: The Joint UK Land Environment Simulator (JULES), model description - Part 2: Carbon fluxes and vegetation dynamics, Geosci. Model Dev., 4, 701-722, doi:10.5194/gmd-4-701-2011, 2011.

Collares-Pereira, M. J., Cowx, I. G., Ribeiro, F., Rodrigues, J. A., and Rogado, L.: Threats imposed by water resource development schemes on the conservation of endangered fish species in the Guadiana River basin in Portugal, Fish. Manage. Ecol., 7, 167178, doi:10.1046/j.1365-2400.2000.00202.x, 2000.
Cox, P. M., Huntingford, C. and Harding, R.: A canopy conductance and photosynthesis model for use in a GCM land surface scheme, J. Hydrol., 212-213, 79-94, doi:10.1016/S0022-1694(98)00203$0,1998$.

Cox, P. M.: Description of the TRIFFID dynamic global vegetation model, Technical Note 24, Hadley Centre, United Kingdom Meteorological Office, Bracknell, UK, 1-16, 2001.

Dadson, S. J., Ashpole, I., Harris, P., Davies, H. N., Clark, D. B., Blyth, E. and Taylor, C. M.: Wetland inundation dynamics in a model of land surface climate: Evaluation in the Niger inland delta region, J. Geophys. Res.-Atmos., 115, D23114, doi:10.1029/2010JD014474, 2010.

Dankers, R., Burke, E. J., and Price, J.: Simulation of permafrost and seasonal thaw depth in the JULES land surface scheme, The Cryosphere, 5, 773-790, doi:10.5194/tc-5-773, 2011.

Dankers, R., Arnell, N. W., Clark, D. B., Falloon, P. D., Fekete, B. M., Gosling, S. N., Heinke, J., Kim, H., Masaki, Y., Satoh, Y., and Stacke, T.: First look at changes in flood hazard in the Inter-Sectoral Impact Model Intercomparison Project ensemble, P. Natl. Acad. Sci., 111, 3257-3261, doi:10.1073/pnas.1302078110, 2014.

Davie, J. C. S., Falloon, P. D., Kahana, R., Dankers, R., Betts, R., Portmann, F. T., Wisser, D., Clark, D. B., Ito, A., Masaki, Y., and Nishina, K.: Comparing projections of future changes in runoff from hydrological and biome models in ISI-MIP, Earth Syst. Dynam., 4, 359-374, doi:10.5194/esd-4-359-2013, 2013.

Döll, P. and Schmied, H. M.: How is the impact of climate change on river flow regimes related to the impact on mean annual runoff? A global-scale analysis, Environ. Res. Lett., 7, 014037, doi:10.1088/1748-9326/7/1/014037, 2012.

Ehret, U., Zehe, E., Wulfmeyer, V., Warrach-Sagi, K., and Liebert, J.: HESS Opinions "Should we apply bias correction to global and regional climate model data?", Hydrol. Earth Syst. Sci., 16, 3391-3404, doi:10.5194/hess-16-3391-2012, 2012.

England, M. H., Kajtar, J. B., and Maher, N.: Robust warming projections despite the recent hiatus, Nat. Clim. Change, 5, 394-396, doi:10.1038/nclimate2575, 2015.

Filipe, A. F., Cowx, I. G., and Collares-Pereira, M. J.: Spatial modelling of freshwater fish in semi-arid river systems: A tool for conservation, River Res. Appl., 18, 123-136, doi:10.1002/rra.638, 2002.

Fischer, E. M. and Knutti, R.: Anthropogenic contribution to global occurrence of heavy-precipitation and hightemperature extremes, Nature Clim. Change, 5, 560-564, doi:10.1038/nclimate2617, 2015.

Fleig, A. K., Tallaksen, L. M., Hisdal, H., and Demuth, S.: A global evaluation of streamflow drought characteristics, Hydrol. Earth Syst. Sci., 10, 535-552, doi:10.5194/hess-10-535-2006, 2006.

Forzieri, G., Feyen, L., Rojas, R., Flörke, M., Wimmer, F., and Bianchi, A.: Ensemble projections of future streamflow droughts in Europe, Hydrol. Earth Syst. Sci., 18, 85-108, doi:10.5194/hess-18-85-2014, 2014.

Fung, F., Lopez, A. and New, M.: Water availability in $+2{ }^{\circ} \mathrm{C}$ and $+4{ }^{\circ} \mathrm{C}$ worlds, Phil. Trans. Roy. Soc. Lnd. A-Math Phys. Eng. Sci., 369, 99-116, doi:10.1098/rsta.2010.0293, 2011.

Giuntoli, I., Vidal, J.-P., Prudhomme, C., and Hannah, D. M.: Future hydrological extremes: the uncertainty from multiple global climate and global hydrological models, Earth Syst. Dynam., 6, 267-285, doi:10.5194/esd-6-267-2015, 2015. 
Gosling, S. N. and Arnell, N. W.: A global assessment of the impact of climate change on water scarcity, Clim. Change, 1-15, doi:10.1007/s10584-013-0853-x, 2013.

Grillakis, M. G., Koutroulis, A. G., and Tsanis, I. K.: Multisegment statistical bias correction of daily GCM precipitation output, J. Geophys. Res.-Atmos., 118, 3150-3162, doi:10.1002/jgrd.50323, 2013.

Gudmundsson, L. and Seneviratne, S. I.: Towards observationbased gridded runoff estimates for Europe, Hydrol. Earth Syst. Sci., 19, 2859-2879, doi:10.5194/hess-19-2859-2015, 2015.

Gudmundsson, L., Tallaksen, L. M., Stahl, K., Clark, D. B., Dumont, E., Hagemann, S., Bertrand, N., Gerten, D., Heinke, J., Hanasaki, N., Voss, F., and Koirala, S.: Comparing large-scale hydrological model simulations to observed runoff percentiles in Europe, J. Hydrometeorol., 13, 604-620, doi:10.1175/JHM-D11-083.1, 2012a.

Gudmundsson, L., Wagener, T., Tallaksen, L. M., and Engeland, K.: Evaluation of nine large-scale hydrological models with respect to the seasonal runoff climatology in Europe, Water Resour. Res., 48, 1-20, doi:10.1029/2011WR010911, 2012b.

Haddeland, I., Clark, D. B., Franssen, W., Ludwig, F., Voß, F., Arnell, N. W., Bertrand, N., Best, M., Folwell, S., Gerten, D., Gomes, S., Gosling, S. N., Hagemann, S., Hanasaki, N., Harding, R., Heinke, J., Kabat, P., Koirala, S., Oki, T., Polcher, J., Stacke, T., Viterbo, P., Weedon, G. P., and Yeh, P.: Multimodel Estimate of the Global Terrestrial Water Balance: Setup and First Results, J. Hydrometeorol., 12, 869-884, doi:10.1175/2011JHM1324.1, 2011.

Haerter, J. O., Hagemann, S., Moseley, C., and Piani, C.: Climate model bias correction and the role of timescales, Hydrol. Earth Syst. Sci., 15, 1065-1079, doi:10.5194/hess-15-10652011, 2011.

Hagemann, S., Chen, C., Haerter, J. O., Heinke, J., Gerten, D., and Piani, C.: Impact of a Statistical Bias Correction on the Projected Hydrological Changes Obtained from Three GCMs and Two Hydrology Models, J. Hydrometeorol., 12, 556-578, doi:10.1175/2011JHM1336.1, 2011.

Hagemann, S., Chen, C., Clark, D. B., Folwell, S., Gosling, S. N., Haddeland, I., Hanasaki, N., Heinke, J., Ludwig, F., Voss, F., and Wiltshire, A. J.: Climate change impact on available water resources obtained using multiple global climate and hydrology models, Earth Syst. Dynam., 4, 129-144, doi:10.5194/esd4-129-2013, 2013.

Hanasaki, N., Inuzuka, T., Kanae, S., and Oki, T.: An estimation of global virtual water flow and sources of water withdrawal for major crops and livestock products using a global hydrological model, J. Hydrol., 384, 232-244, doi:10.1016/j.jhydrol.2009.09.028, 2010.

Harding, R. J., Weedon, G. P., van Lanen, H. A. J. and Clark, D. B.: The future for Global Water Assessment, J. Hydrol., 518, 186193, doi:10.1016/j.jhydrol.2014.05.014, 2014.

Haylock, M. R., Hofstra, N., Klein Tank, A. M. G., Klok, E. J., Jones, P. D., and New, M.: A European daily high-resolution gridded dataset of surface temperature and precipitation, J. Geophys. Res., 113, D20119, doi:10.1029/2008JD010201, 2008.

Jiménez, C., Clark, D. B., Kolassa, J., Aires, F., and Prigent, C.: A joint analysis of modeled soil moisture fields and satellite observations, J. Geophys. Res.-Atmos., 118, 6771-6782, doi:10.1002/jgrd.50430, 2013.
Koirala, S., Hirabayashi, Y., Mahendran, R., and Kanae, S.: Global assessment of agreement among streamflow projections using CMIP5 model outputs, Environ. Res. Lett., 9, 064017, doi:10.1088/1748-9326/9/6/064017, 2014.

Laizé, C. L. R., Acreman, M. C., Schneider, C., Dunbar, M. J., Houghton-Carr, H. A., Flörke, M., and Hannah, D. M.: Projected flow alteration and ecological risk for pan-european rivers, River Res. Appl., 30, 299-314, doi:10.1002/rra.2645, 2014.

Liu, M., Rajagopalan, K., Chung, S. H., Jiang, X., Harrison, J., Nergui, T., Guenther, A., Miller, C., Reyes, J., Tague, C., Choate, J., Salathé, E. P., Stöckle, C. O., and Adam, J. C.: What is the importance of climate model bias when projecting the impacts of climate change on land surface processes?, Biogeosciences, 11, 2601-2622, doi:10.5194/bg-11-2601-2014, 2014.

MacKellar, N. C., Dadson, S. J., New, M., and Wolski, P.: Evaluation of the JULES land surface model in simulating catchment hydrology in Southern Africa, Hydrol. Earth Syst. Sci. Discuss., 10, 11093-11128, doi:10.5194/hessd-10-11093-2013, 2013.

Marthews, T. R., Malhi, Y., Girardin, C. A., Silva Espejo, J. E., Aragão, L. E., Metcalfe, D. B., Rapp, J. M., Mercado, L. M., Fisher, R. A., Galbraith, D. R., and Fisher, J. B.: Simulating forest productivity along a neotropical elevational transect: temperature variation and carbon use efficiency, Global Change Biol., 18, 2882-2898, doi:10.1111/j.1365-2486.2012.02728.x, 2012.

Moore, R. J.: The probability-distributed principle and runoff production at point and basin scales, Hydrolog. Sci. J., 30, 273-297, doi:10.1080/02626668509490989, 1985.

Muerth, M. J., Gauvin St-Denis, B., Ricard, S., Velázquez, J. A., Schmid, J., Minville, M., Caya, D., Chaumont, D., Ludwig, R., and Turcotte, R.: On the need for bias correction in regional climate scenarios to assess climate change impacts on river runoff, Hydrol. Earth Syst. Sci., 17, 1189-1204, doi:10.5194/hess-171189-2013, 2013.

Oki, T. and Sud, Y. C.: Design of Total Runoff Integrating Pathways (TRIP) - A global river channel network, Earth interact., 2, 1-37, 1998.

Parry, S., Hannaford, J., Lloyd-Hughes, B., and Prudhomme, C.: Multi-year droughts in Europe: analysis of development and causes, Hydrol. Res., 43, 689-706, 2012.

Penman, H. L.: Natural evaporation from open water, bare soil and grass, P. Roy. Soc. Lond. A, 193, 120-145, 1948.

Pires, A., Cowx, I., and Coelho, M.: Seasonal changes in fish community structure of intermittent streams in the middle reaches of the Guadiana basin, Portugal, J. Fish Biol., 54, 235-249, doi:10.1006/jfbi.1998.0860, 1999.

Prudhomme, C., Parry, S., Hannaford, J., Clark, D. B., Hagemann, S., and Voss, F.: How Well Do Large-Scale Models Reproduce Regional Hydrological Extremes in Europe?, J. Hydrometeorol., 12, 1181-1204, doi:10.1175/2011JHM1387.1, 2011.

Prudhomme, C., Giuntoli, I., Robinson, E. L., Clark, D. B., Arnell, N. W., Dankers, R., Fekete, B. M., Franssen, W., Gerten, D., Gosling, S. N., Hagemann, S., Hannah, D. M., Kim, H., Masaki, Y., Satoh, Y., Stacke, T., Wada, Y., and Wisser, D.: Hydrological droughts in the 21st century, hotspots and uncertainties from a global multimodel ensemble experiment, P. Natl. Acad. Sci. USA, 111, 3262-3267, doi:10.1073/pnas.1222473110, 2014.

Pryor, M., Clark, D., Harris, P., and Hendry, M.: Joint UK Land Environment Simulator (JULES) Version 3.2 User Manual, 2012. 
Richards, L. A.: Capillary conduction of liquids through porous mediums, J. Appl. Phys., 1, 318-333, 1931.

Sanford, T., Frumhoff, P. C., Luers, A., and Gulledge, J.: The climate policy narrative for a dangerously warming world, Nat. Clim. Change, 4, 164-166, 2014.

Schewe, J., Heinke, J., Gerten, D., Haddeland, I., Arnell, N. W., Clark, D. B., Dankers, R., Eisner, S., Fekete, B. M., ColónGonzález, F. J., Gosling, S. N., Kim, H., Liu, X., Masaki, Y., Portmann, F. T., Satoh, Y., Stacke, T., Tang, Q., Wada, Y., Wisser, D., Albrecht, T., Frieler, K., Piontek, F., Warszawski, L. and Kabat, P.: Multimodel assessment of water scarcity under climate change, P. Natl. Acad. Sci. USA, 111, 3245-3250, doi:10.1073/pnas.1222460110, 2014.

Schneider, C., Laizé, C. L. R., Acreman, M. C., and Flörke, M.: How will climate change modify river flow regimes in Europe?, Hydrol. Earth Syst. Sci., 17, 325-339, doi:10.5194/hess-17-3252013, 2013.

Sung, J. H. and Chung, E.-S.: Development of streamflow drought severity-duration-frequency curves using the threshold level method, Hydrol. Earth Syst. Sci., 18, 3341-3351, doi:10.5194/hess-18-3341-2014, 2014.

Tallaksen, L., Madsen, H., and Clausen, B.: On the definition and modelling of streamflow drought duration and deficit volume, Hydrolog. Sci. J., 42, 15-33, doi:10.1080/02626669709492003, 1997.

Teng, J., Potter, N. J., Chiew, F. H. S., Zhang, L., Wang, B., Vaze, J., and Evans, J. P.: How does bias correction of regional climate model precipitation affect modelled runoff?, Hydrol. Earth Syst. Sci., 19, 711-728, doi:10.5194/hess-19-711-2015, 2015.

Teutschbein, C. and Seibert, J.: Bias correction of regional climate model simulations for hydrological climate-change impact studies: Review and evaluation of different methods, J. Hydrol., 456457, 12-29, doi:10.1016/j.jhydrol.2012.05.052, 2012.

Van den Hoof, C., Vidale, P. L., Verhoef, A., and Vincke, C.: Improved evaporative flux partitioning and carbon flux in the land surface model JULES: Impact on the simulation of land surface processes in temperate Europe, Agricult. For. Meteorol., 181, 108-124, doi:10.1016/j.agrformet.2013.07.011, 2013.

van Huijgevoort, M. H. J., Hazenberg, P., van Lanen, H. A. J., Teuling, A. J., Clark, D. B., Folwell, S., Gosling, S. N., Hanasaki, N., Heinke, J., Koirala, S., Stacke, T., Voss, F., Sheffield, J., and Uijlenhoet, R.: Global Multimodel Analysis of Drought in Runoff for the Second Half of the Twentieth Century, J. Hydrometeorol., 14, 1535-1552, doi:10.1175/JHM-D-12-0186.1, 2013.

Van Vliet, M. T. H., Franssen, W. H. P., Yearsley, J. R., Ludwig, F., Haddeland, I., Lettenmaier, D. P., and Kabat, P.: Global river discharge and water temperature under climate change, Global Environ. Change, 23, 450-464, doi:10.1016/j.gloenvcha.2012.11.002, 2013.

Vautard, R., Gobiet, A., Jacob, D., Belda, M., Colette, A., Déqué, M., Fernández, J., García-Díez, M., Goergen, K., Güttler, I., Halenka, T., Karacostas, T., Katragkou, E., Keuler, K., Kotlarski, S., Mayer, S., van Meijgaard, E., Nikulin, G., Patarčić, M., Scinocca, J., Sobolowski, S., Suklitsch, M., Teichmann, C., Warrach-Sagi, K., Wulfmeyer, V., and Yiou, P.: The simulation of European heat waves from an ensemble of regional climate models within the EURO-CORDEX project, Clim. Dynam., 41, 2555-2575, doi:10.1007/s00382-013-1714-z, 2013.
Vautard, R., Gobiet, A., Sobolowski, S., Kjellström, E., Stegehuis, A., Watkiss, P., Mendlik, T., Landgren, O., Nikulin, G., Teichmann, C., and Jacob, D.: The European climate under a $2{ }^{\circ} \mathrm{C}$ global warming, Environ. Res. Lett., 9, 034006, doi:10.1088/1748-9326/9/3/034006, 2014.

Vicente-Serrano, S. M., Lopez-Moreno, J.-I., Beguería, S., Lorenzo-Lacruz, J., Sanchez-Lorenzo, A., García-Ruiz, J. M., Azorin-Molina, C., Morán-Tejeda, E., Revuelto, J., Trigo, R., Coelho, F., and Espejo, F.: Evidence of increasing drought severity caused by temperature rise in southern Europe, Environ. Res. Lett., 9, 044001, doi:10.1088/1748-9326/9/4/044001, 2014.

Vrochidou, A. E. K., Tsanis, I. K., Grillakis, M. G., and Koutroulis, A. G.: The impact of climate change on hydrometeorological droughts at a basin scale, J. Hydrol., 476, 290-301, doi:10.1016/j.jhydrol.2012.10.046, 2013.

Wanders, N. and Van Lanen, H. A. J.: Future discharge drought across climate regions around the world modelled with a synthetic hydrological modelling approach forced by three general circulation models, Nat. Hazards Earth Syst. Sci., 15, 487-504, doi:10.5194/nhess-15-487-2015, 2015.

Wanders, N., Wada, Y., and Van Lanen, H. A. J.: Global hydrological droughts in the 21 st century under a changing hydrological regime, Earth Syst. Dynam., 6, 1-15, doi:10.5194/esd-6-1-2015, 2015.

Warszawski, L., Frieler, K., Huber, V., Piontek, F., Serdeczny, O., and Schewe, J.: The Inter-Sectoral Impact Model Intercomparison Project (ISI-MIP): Project framework, P. Natl. Acad. Sci. USA, 111, 3228-3232, 2014.

Weedon, G. P., Gomes, S., Viterbo, P., Österle, H., Adam, J. C., Bellouin, N., Boucher, O., and Best, M.: The WATCH forcing data 1958-2001: A meteorological forcing dataset for land surface and hydrological models, WATCH Tech. Rep. 22, 41, available online at http://www.eu-watch.org/publications/ technical-reports, 2010

Weedon, G. P., Balsamo, G., Bellouin, N., Gomes, S., Best, M. J., and Viterbo, P.: The WFDEI meteorological forcing data set: WATCH Forcing Data methodology applied to ERAInterim reanalysis data, Water Resour. Res., 50, 7505-7514, doi:10.1002/2014WR015638, 2014.

Weedon, G. P., Prudhomme, C., Crooks, S., Ellis, R. J., Folwell, S. S., and Best, M. J.: Evaluating the Performance of Hydrological Models via Cross-Spectral Analysis: Case Study of the Thames Basin, United Kingdom, J. Hydrometeorol., 16, 214 231, doi:10.1175/JHM-D-14-0021.1, 2015.

World Bank: Turn Down the Heat: Confronting the New Climate Normal. Washington, DC: World Bank. License: Creative Commons Attribution-NonCommercial-NoDerivatives 3.0 IGO (CC BY-NC-ND 3.0 IGO), 2014.

Zulkafli, Z., Buytaert, W., Onof, C., Lavado, W., and Guyot, J. L.: A critical assessment of the JULES land surface model hydrology for humid tropical environments, Hydrol. Earth Syst. Sci., 17, 1113-1132, doi:10.5194/hess-17-1113-2013, 2013. 